\title{
$\beta 1$ integrins regulate chondrocyte rotation, G1 progression, and cytokinesis
}

\author{
Attila Aszodi, ${ }^{1}$ Ernst B. Hunziker, ${ }^{2}$ Cord Brakebusch, ${ }^{1}$ and Reinhard Fässler ${ }^{1,3}$ \\ ${ }^{1}$ Max Planck Institute for Biochemistry, Department for Molecular Medicine, 82152 Martinsried, Germany; ${ }^{2}$ ITI Research \\ Institute for Dental and Skeletal Biology, University of Bern, 3010 Bern, Switzerland
}

$\beta 1$ integrins are highly expressed on chondrocytes, where they mediate adhesion to cartilage matrix proteins. To assess the functions of $\beta 1$ integrin during skeletogenesis, we inactivated the $\beta 1$ integrin gene in chondrocytes. We show here that these mutant mice develop a chondrodysplasia of various severity. 及1-deficient chondrocytes had an abnormal shape and failed to arrange into columns in the growth plate. This is caused by a lack of motility, which is in turn caused by a loss of adhesion to collagen type II, reduced binding to and impaired spreading on fibronectin, and an abnormal F-actin organization. In addition, mutant chondrocytes show decreased proliferation caused by a defect in G1/S transition and cytokinesis. The G1/S defect is, at least partially, caused by overexpression of Fgfr3, nuclear translocation of Stat1/Stat5a, and up-regulation of the cell cycle inhibitors p16 and p21. Altogether these findings establish that $\beta 1$-integrin-dependent motility and proliferation of chondrocytes are mandatory events for endochondral bone formation to occur.

[Keywords: Integrin; fibronectin; endochondral ossification; growth plate; cytokinesis; FGF]

Supplemental material is available at http://www.genesdev.org.

Received July 1, 2003; revised version accepted July 22, 2003.

The growth plate is a specialized region of the cartilage ensuring longitudinal growth of long bones. Growth plate chondrocytes undergo a sequential differentiation process characterized by proliferation, growth arrest, maturation, and hypertrophy. Eventually, the hypertrophic chondrocytes are replaced by bone. In the proliferative zone, chondrocytes are arranged into columns of 6-8 cells. Doods noted as early as 1930 that chondrocytes, which divide perpendicular to the long axis of the growing bones, must undergo extensive movements to arrange in longitudinal columns (Doods 1930). The molecules involved in this chondrocyte "rotation," however, are still unknown.

Chondrocytes are completely surrounded by a network of extracellular matrix (ECM) proteins and thus lack cell-cell contacts. The interactions of chondrocytes with matrix molecules are believed to regulate, in concert with growth factors and cytokines, their proliferation and differentiation. Likewise, ECM receptors on chondrocytes are supposed to regulate cell adhesion and the correct supramolecular assembly of ECM molecules in cartilage.

Integrins are a major class of cell adhesion molecules that mediate such cell-matrix interactions. They are

${ }^{3}$ Corresponding author.

E-MAIL faessler@biochem.mpg.de; FAX 49-89-8578 2422.

Article and publication are at http://www.genesdev.org/cgi/doi/10.1101/ $\operatorname{gad} .277003$. composed of $\alpha$ and $\beta$ subunits, bind ECM proteins and counter receptors, and regulate various biological processes including the supramolecular assembly of ECM proteins, adhesion and migration of cells, cell cycle progression, cell survival, and differentiation (Bouvard et al. 2001; Brakebusch et al. 2002; Hynes 2002). Chondrocytes express high levels of several $\beta 1$ and $\alpha \mathrm{v}$ integrins (Loeser 2000), which can mediate adhesion to various matrix molecules found in cartilage.

Two in vitro studies suggested an important role of $\beta 1$ integrins in cartilage development and function. Administration of anti- $\beta 1$ antibodies to cultures of mouse limb bud mesenchymal cells inhibits the formation of cartilaginous nodules (Shakibaei 1998), suggesting that $\beta 1$ integrins are essential either during mesenchymal condensation or during chondrocyte differentiation. In organ cultures of chicken sternal cartilage, addition of inhibitory antibodies against $\beta 1$ integrin resulted in reduced sternal growth, a reduction in cell size, a disturbed organization of filamentous actin bundles, the absence of type $\mathrm{X}$ collagen deposition, and increased apoptosis (Hirsch et al. 1997).

To date, such a crucial function of integrins on chondrocytes has not been confirmed using in vivo models. Mice carrying constitutive null mutations in genes of certain individual integrin subunits expressed by chondrocytes have lethal phenotypes prior to chondrocyte differentiation $(\alpha 5, \beta 1)$ and therefore provide little information about their roles in chondrocyte function. However, 
chimeric mice generated with $\beta 1$-integrin-deficient ES cells contained a few mutant chondrocytes, indicating that they can differentiate in the absence of $\beta 1$ integrins in vivo (Fässler and Meyer 1995). Other mutant mice lacking $\alpha 1, \alpha 2, \alpha 6, \alpha v, \beta 3$, or $\beta 5$ integrin do not show an obvious skeletal phenotype (for review, see Bouvard et al. 2001), indicating no or a redundant role in skeletogenesis.

To overcome the problem of embryonic lethality of $\beta 1$-integrin-deficient mice, we generated mice carrying a cartilage-specific deletion of the $\beta 1$ integrin gene. We show that $\beta 1$ integrin mutant chondrocytes are unable to form columns in growth plates and have severe proliferation defects affecting several phases of the cell cycle.

\section{Results \\ Generation of mice lacking $\beta 1$ integrin in chondrocytes}

To assess the function of $\beta 1$ integrins during endochondral bone formation, we crossed mice carrying the floxed $\beta 1$ integrin gene $\left(\beta 1^{f l / f l}\right.$; Potocnik et al. 2000) with mice expressing the cre recombinase under the control of the mouse type II collagen promoter (Col2a1-cre; K. Sakai et al. 2001). In progeny, the cre mediates ablation of the conditional $\beta 1$ integrin allele and activates a promoterless lac $Z$ reporter gene inserted downstream of the second $\operatorname{lox}_{P}$ site (for details, see Brakebusch et al. 2000; Potocnik et al. 2000). Col2a1-cre/ $\beta 1^{f l / w t}$ mice show no abnormalities. Whole-mount X-gal staining of Col2a1cre $/ \beta 1^{f l / w t}$ embryos demonstrated the deletion of the floxed $\beta 1$ integrin gene in Col2a1 expressing chondrogenic and nonchondrogenic tissues. At embryonic day 10.5 (E10.5), strong LacZ activity was observed in all sclerotomes, which contain precursor cells for the anlage of vertebral bodies (Fig. 1A). At E12.5, the areas of prechondrogenic, as well the chondrogenic elements of the axial and appendicular skeleton, showed LacZ activities (data not shown).

Col2a1-cre/ $\beta 1^{f 1 / w t}$ males were crossed with females carrying either two floxed $\beta 1$ alleles or one floxed and one constitutive null (n) allele (Fässler and Meyer 1995). Col2a1-cre/ $\beta 1^{f l / f 1}$ and Col2a1-cre/ $\beta 1^{f 1 / n}$ offspring developed chondrodysplasia and were phenotypically indistinguishable from one another. Therefore we refer to both types as mutant $(\mathrm{m})$ mice. Immunostaining of mutant mice at E11.5 revealed a virtually complete loss of $\beta 1$
Figure 1. Deletion of the of $\beta 1$ integrin gene and gross morphology of mutants. $(A)$ Demonstration of the cre-mediated deletion of $\beta 1$ integrin gene by whole-mount $\mathrm{X}$-gal staining in E10.5 embryo heterozygous for the floxed $\beta 1$ integrin allele and Col2a1-cre transgene. Note the strong LacZ activity in somites (s). (B) $\beta 1$ integrin immunostaining (IHC) and X-gal staining in the developing vertebral column at E11.5. In wild type ( $\mathrm{w}), \beta 1$ integrin expression was high at the areas of precartilaginous condensation of prevertebrae (pv), whereas mutant $(\mathrm{m})$ prevertebrae lacked $\beta 1$ integrin expression and displayed strong LacZ activity. $(C)$ Immunostaining for $\beta 1$ integrin in newborn (NB) tibia showed absent $\beta 1$ integrin staining on mutant growth plate chondrocytes and in the perichondrium (p). Asterisk indicates a $\beta 1$-integrinpositive vessel in the mutant perichondrium. (D) FACS analysis of primary rib chondrocytes confirmed the absence of $\beta 1$ integrin, and $\beta 1$ integrin-associated $\alpha$ subunits $(\alpha 1, \alpha 5$, and $\alpha 6)$ on mutant cells. $(E)$ Alizarin-red and alcian-blue double skeletal staining for bony and cartilaginous tissues, respectively, revealed the presence of all skeletal elements in mutant mice. Closer view of the forelimb indicated that the long bones [(h) humerus; $(\mathrm{r})$ radius; $(\mathrm{u})$ ulna] are shorter and broader. (F) X-ray analysis at 9 wk of age revealed a further size reduction and mild lordosis of mutant compared with control. (Insets) Closer view on the hindlimb showed broadened bones but no apparent alteration of the bone density.
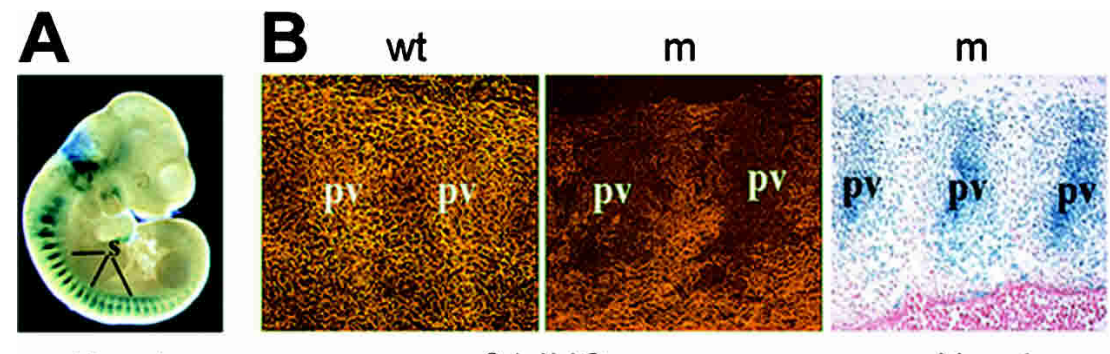

X-gal

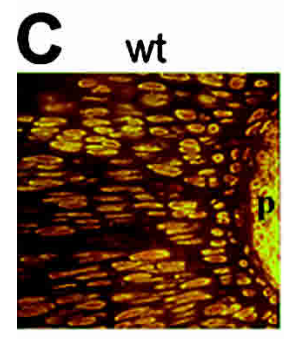

$\beta 1 \mathrm{IHC}$

X-gal
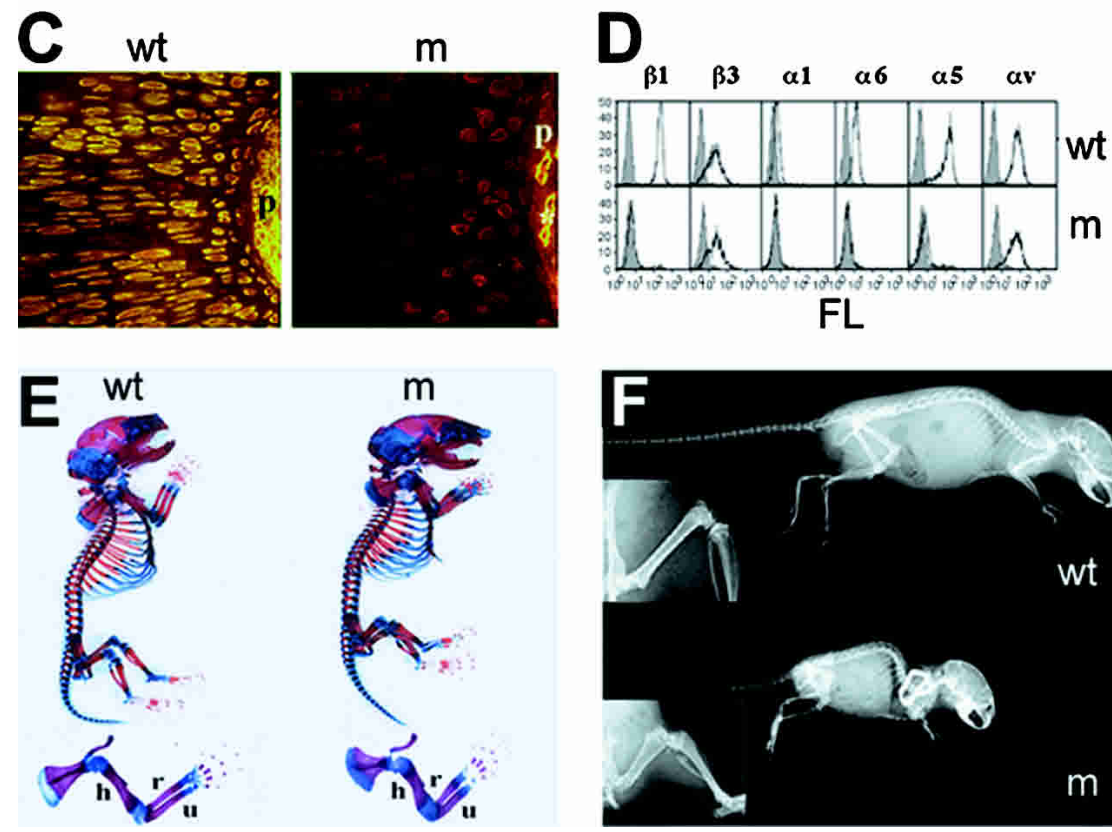

$\mathrm{FL}$
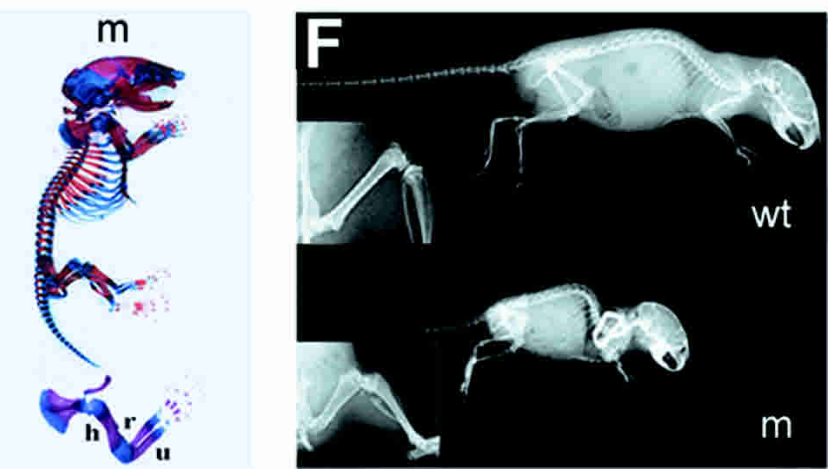
integrin in the areas of condensing prevertebrae, where also the lacZ activity was strong (Fig. 1B). At E12.5, the developing cartilaginous anlage of the future long bones showed still a very faint $\beta 1$ integrin immunostaining (data not shown), whereas at E14.5 and E17.5, epiphyseal and growth plate chondrocytes and perichondrial cells completely lacked $\beta 1$ integrin expression (Fig. 1C; data not shown). The loss of $\beta 1$ integrin was further confirmed by Northern and FACS analysis. RNA samples from primary chondrocytes showed no signal with a probe specific for $\beta 1$ integrin (data not shown). FACS analysis of isolated rib chondrocytes revealed the loss of $\beta 1$ integrin and $\beta 1$ integrin-associated $\alpha$ subunits $\mid \alpha 1, \alpha 2$, $\alpha 5$, and $\alpha 6$ ) on the surface of mutant cells (Fig. 1D; data not shown). The expression level of $\alpha \mathrm{v} \beta 3$ was unchanged on mutant chondrocytes (Fig. 1D).

\section{Loss of $\beta 1$ integrin in cartilage results in a} severe chondrodysplasia

Most mutant mice died shortly after birth because of respiratory distress. Newborn mice were shorter compared with controls (Fig. 1E), and $~ 50 \%$ of them had cleft palate. Out of 223 mutant offspring, only 3 survived and developed progressive dwarfism (Fig. 1F).
Whole-mount skeletal staining of E17.5 embryos demonstrated that both bone and cartilage were present in mutants (Fig. 1E). Their long bones were shortened and broadened (Fig. 1E). The ossification centers of the cervical vertebrae were not visible in mutants, indicating a delay in mineralization (data not shown).

Histological analysis revealed that the cartilaginous anlage of mutant long bones appeared normal until E13 (data not shown). At E14.5, the length of the mutant humerus was significantly shorter (Fig. 2A,C), the zone of hypertrophic cells was reduced, and the mineralization and vascularization of the central part of the anlage were delayed (Fig. 2B,D). At E17.5, mutant bones were severely shortened (Fig. 2E,H). Significant reductions of the half tibial length $(17.2 \%, p<0.01)$, the distance between the growth plate and the middle of diaphysis $(43.2 \%, p<0.001)$, the length of the bone marrow zone $(45 \%, p<0.001)$, and the length of the hypertophic zone $(15 \%, p<0.05)$ were observed in mutants compared with controls. The length of the resting zone was significantly increased in mutants $(10 \%, p<0.05)$, whereas the length of the proliferative zone and the total growth plate height were similar.

The reduced growth performance of mutant bones was associated with a severe disorganization of the growth plate (Fig. 2, cf. F and I). In normal growth plate, the

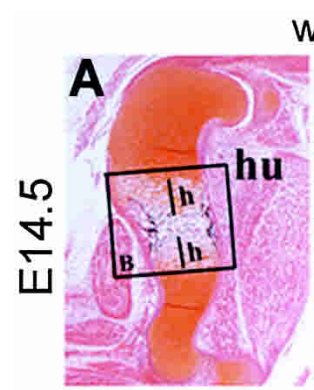

wt
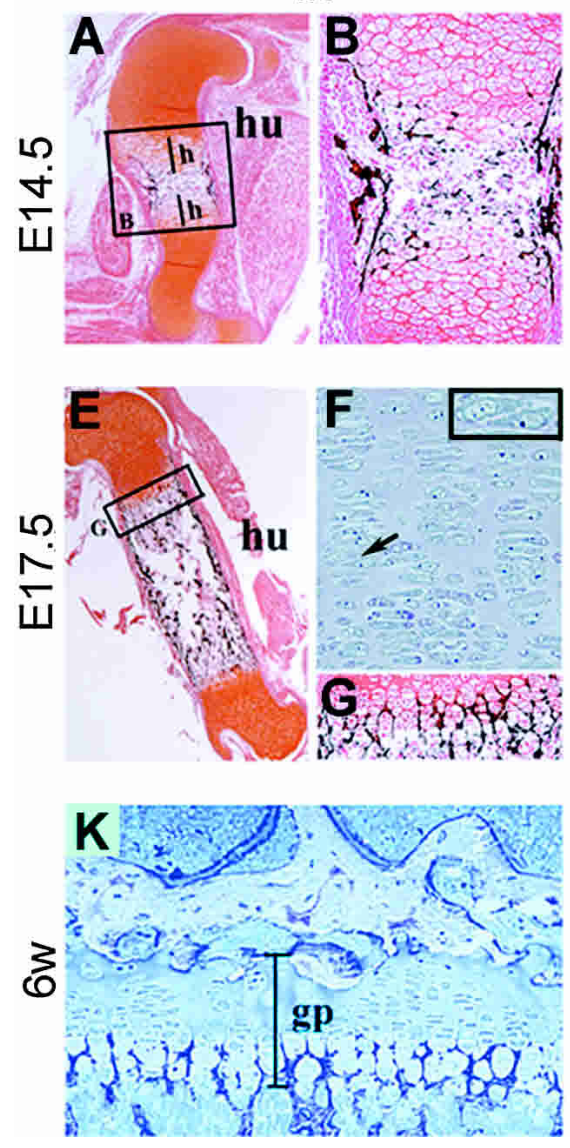

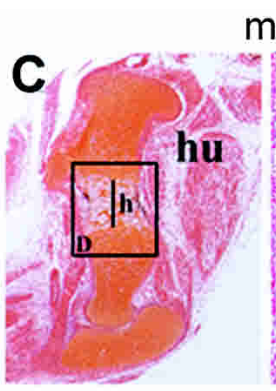

$m$
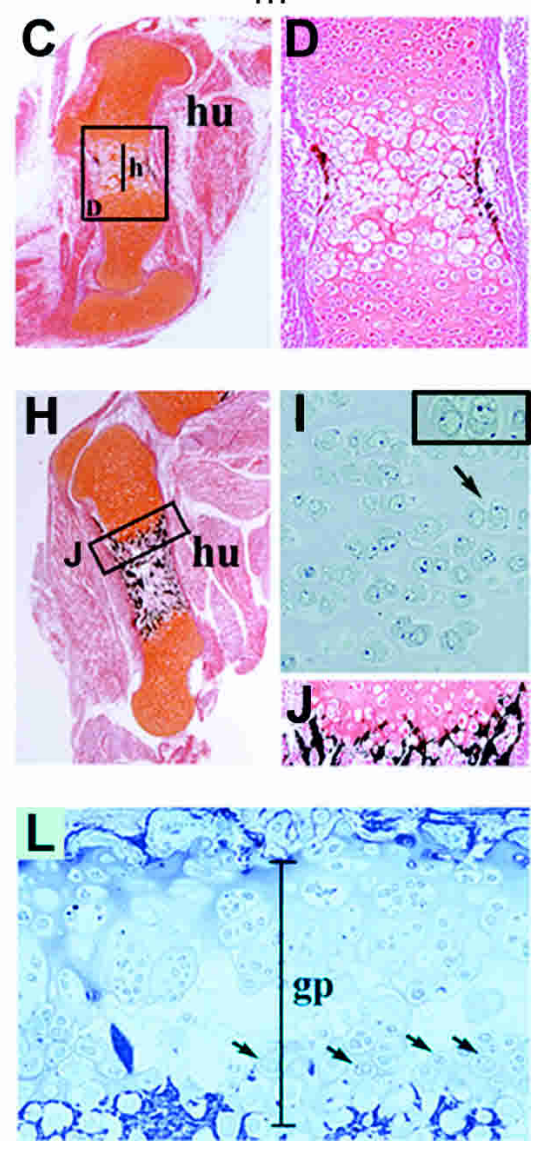

Figure 2. Histological analysis of endochondral bone formation in wild-type $(\mathrm{wt})$ and mutant $(\mathrm{m})$ mice. $(A-D, E, G, H, J)$ Safranin-orange-van Kossa staining. $(F, I, K, L)$ Toulidin-blue staining. $(A-D)$ At E14.5, the mutant humerus $(\mathrm{hu} ; C)$ was significantly shorter, and the central hypertrophic region (h) was reduced compared with wild-type humerus $(A)$. $(B)$ Higher magnification demonstrates the vascular invasion of the primary ossification center, and the mineralization of the bone collar and the matrix of the terminal hypertophic chondrocytes in wild type. $(D)$ On the contrary, no vascularization was observed in the mutant, and the mineralization was restricted to the periosteum. $(E-J)$ At E17.5, the metaphysis of the mutant humerus was greatly shortened with distinct trabeculae and bone collar $(H)$. The typical columnar arrangement of the growth plate chondrocytes seen in the wild type $(F)$ was disorganized in the mutant $(I)$. $(F$, inset) Two rotating chondrocytes (arrow). In the mutant growth plate $(I)$, the chondrocytes lie side by side (arrow and inset) and were fewer in number. The longitudinal septae of the terminal hypertrophic chondrocytes showed fewer and patchy mineral deposits in the mutant (J) compared with those in wild type $(G) .(K, L)$ Growth plate (gp) morphology in tibia of 6-week-old mice. The growth plate was broadened in the mutant, lacked the columnar organization $(\mathrm{L})$, and contained binucleate chondrocytes (arrows). 
proliferative chondrocytes are flattened, and during cell division, their mitotic figures are always oriented perpendicular to the long axis of the bone. The two daughter cells are semicircular, lie side by side in the lacuna, and become discoid again through extensive cell shape changes and rotational movements within the lacuna (Fig. 2F, see inset; Doods 1930). In $\beta 1$-null growth plates, the large and round-shaped chondrocytes also show mitotic figures perpendicular to the long axis /data not shown), but their shape did not change, they stayed side by side and failed to glide over each other and form columns (Fig. 2I, see inset) and calcified longitudinal septae (Fig. 2J). This abnormal rotational movement of mutant chondrocytes resulted in a broadening of the growth plate and a reduced longitudinal growth (Figs. 1F, 2E,H). In addition, the number of chondrocytes was decreased, whereas the extracellular space was greatly increased between chondrocytes in each zone of the mutant growth plate (Fig. 2F,I).

A few mutant mice survived. They developed a severe dwarfism and had a $40 \%$ shorter skeleton at 9 wk of age (Fig. 1F). Histological analysis of 3 -week-old mutant mice showed delayed formation of secondary ossification centers in the epiphysis and a reduced hypertophic zone of growth plate (data not shown). The cortical bone appeared normal, but the length of the trabecular bones was reduced in the primary spongiosa (data not shown). At 6 wk of age, the mutant growth plate was completely disorganized and broadened compared with control (Fig. $2 \mathrm{~K}, \mathrm{~L})$. Large, cell-free matrix areas and binucleate chondrocytes were frequently detected (Fig. 2L).

\section{Mutant chondrocytes show adhesion and spreading defects}

Because most of the cartilage ECM molecules bind chondrocytes via their cognate integrin (Loeser 2000), the growth plate abnormalities of $\beta 1$ integrin mutant bones could be explained by a complete or partial loss of chondrocyte-substrate interactions. Several studies with human and bovine chondrocytes demonstrated that integrins $\alpha 1 \beta 1, \alpha 2 \beta 1$, and $\alpha 10 \beta 1$ are receptors for collagen type II; $\alpha 1 \beta 1$ and $\alpha 6 \beta 1$ for laminin; $\alpha 5 \beta 1, \alpha \mathrm{v} \beta 3$, and $\alpha \mathrm{v} \beta 5$ for fibronectin (FN); and $\alpha \mathrm{v} \beta 3$ and $\alpha \mathrm{v} \beta 5$ for vitronectin. To investigate $\beta 1$-integrin-mediated chondrocyte-ECM interactions, we performed adhesion assays with freshly isolated chondrocytes from the rib cages of normal and mutant mice (Fig. 3A). Mutant cells completely lost their ability to adhere to type II collagen and laminin. Although adhesion of mutant chondrocytes to fibronectin was reduced by $\sim 55 \%$, they adhered normally to vitronectin. Staining with phalloidin and antibodies against focal adhesion (FA) proteins (paxillin, zyxin, vinculin) demonstrated reduced spreading, but normal actin stress fibers and FA formation of mutant cells on vitronectin (Fig. 3B; data not shown). Mutant cells spread significantly less on fibronectin and showed rounded appearance. They displayed fewer and thinner stress fibers and showed an increased peripheral actin staining. Normal chondrocytes formed FAs, which were evenly distributed throughout the cells. Mutant chondrocytes had fewer FAs, which were concentrated at the cell periphery (Fig. 3B).
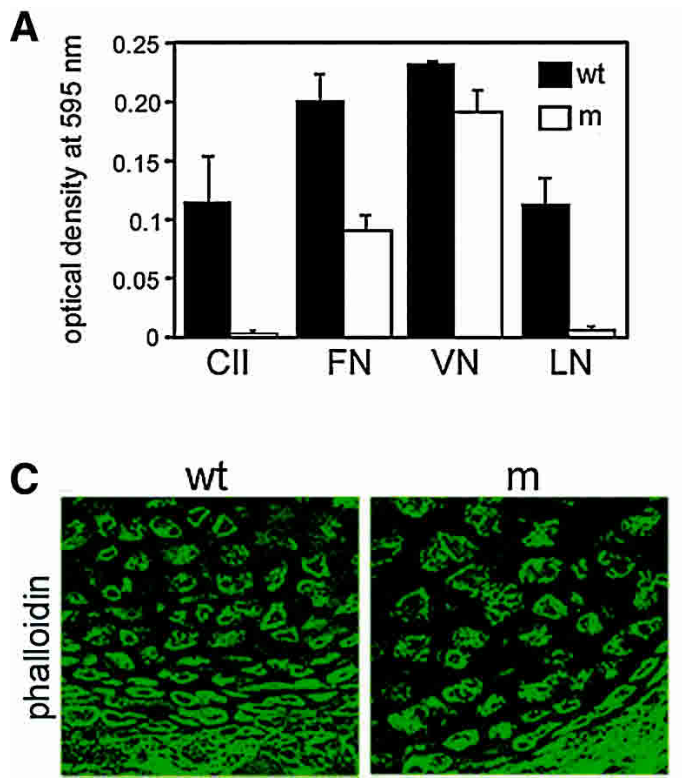

B

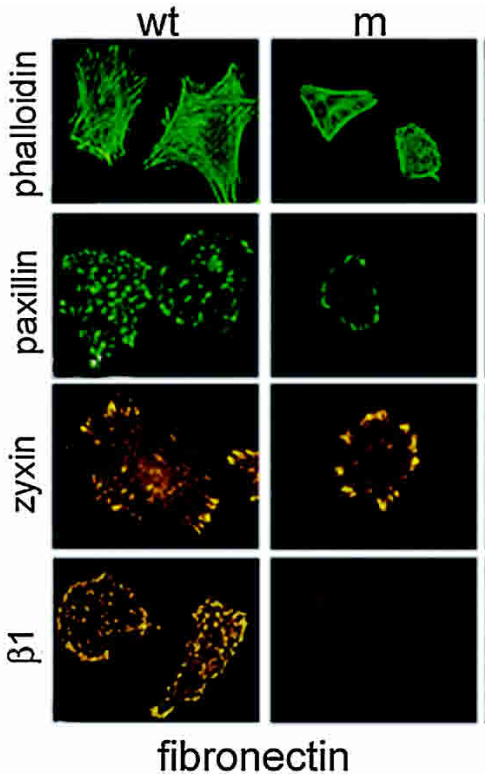

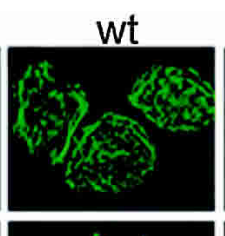
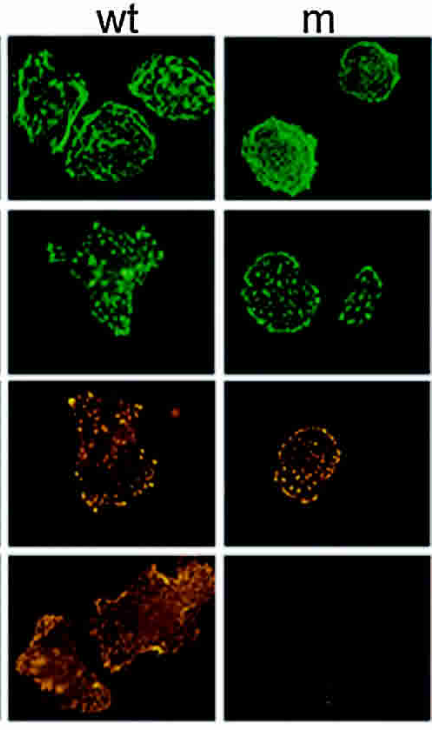

vitronectin

Figure 3. Adhesion and spreading abnormalities of mutant primary chondrocytes. (A) Adhesion assay. Lack of adhesion of mutant chondrocytes to collagen II (CII) and laminin I (LN), reduced adhesion to fibronectin (FN), and normal adhesion to vitronectin (VN). The numbers represent the mean adhesion; error bars represent SD. (B) Spreading assay. Mutant chondrocytes showed impaired spreading on fibronectin with less actin stress fibers and reduced recruitment of FA proteins (paxillin, zyxin). On vitronectin, the spreading of mutant chondrocytes was less affected. $(C)$ Confocal microscopy of actin distribution in chondrocytes of epiphyseal cartilage. Wild-type chondrocytes showed even cortical staining with phalloidin. Mutant cells display a punctuated actin distribution. 
Next, we assessed the cytoskeletal organization in vivo. Confocal microscopy on tissue sections stained with phalloidin showed an even cortical actin ring in wild-type chondrocytes, whereas the actin distribution was punctate in mutant cells (Fig. 3C). Immunostaining for vimentin and tubulin did not reveal detectable differences between wild-type and mutant tissue (data not shown).

\section{$\beta 1$ integrins control collagen fibril assembly}

Next, we analyzed the organization of collagen fibrils at the ultrastructural level. Electron microscopy of E17.5 and 6-week-old limb cartilage (Fig. 4A-D) revealed abnormal distribution of collagen fibrils in the mutant growth plates. At E17.5, the fibrillar density was normal in the resting zone (data not shown), but reduced in the interterritorial (Fig. 4A) and territorial/pericellular matrix (Fig. 4B) of the proliferative and hypertrophic zones (data not shown). At 6 wk of age, areas with greatly reduced fibrillar density were observed in all zones of mutant cartilage (Fig. 4D; data not shown). Furthermore, the fibrils had an unusual variation in diameter and tended to form parallel fibrillar bundles instead of a fibrillar network (Fig. 4C; data not shown).

It has been shown that $\alpha 5 \beta 1$-dependent assembly of fibronectin on the cell surface of cultured fibroblast regu- lates collagen deposition and fibril assembly (Velling et al. 2002). Because the abnormal collagen network in $\beta 1$ deficient cartilage might account for the structural abnormalities of the growth plate, we investigated the role of FN during endochondral bone formation in mice lacking FN expression in cartilage. The FN mutant mice were obtained by crossing Col2a1-cre mice with floxed fibronectin mice (T. Sakai et al. 2001). Surprisingly, the Col2a1-cre/FN $N^{f l / f 1}$ mice developed normally and did not show skeletal abnormalities. The loss of fibronectin expression in cartilage was shown by immunostaining with a polyclonal anti-fibronectin antibody, which detects all fibronectin isoforms (Fig. 4E). Histological investigation of growth plates and articular cartilage up to 2 mo of age (Fig. 4F) and X-ray analysis of a 9-month-old mutant mouse (Fig. 4G) revealed a normal skeleton, indicating that fibronectin has no rate-limiting role during endochondral bone formation.

\section{Impaired cartilage differentiation}

To investigate the differentiation properties of $\beta 1$-integrin-deficient chondrocytes, we performed Northern blot, immunohistochemical, in situ hybridization analyses, and histochemical tests using markers for chondrogenesis, vasculogenesis, and osteogenesis at E17.5. Immunostaining for matrix proteins that interact with $\beta 1$ integrins including collagen type II, fibronectin, and
A

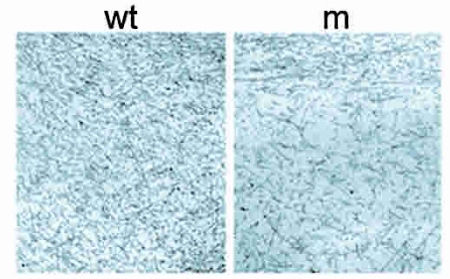

B

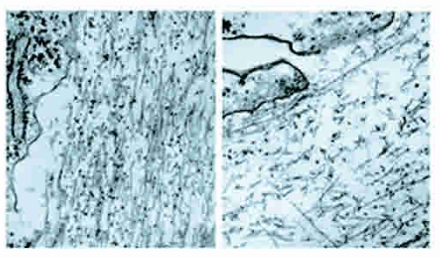

C

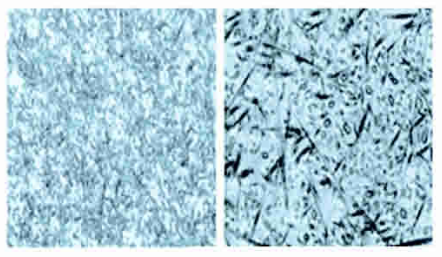

D

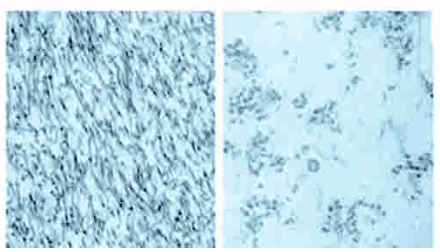

E

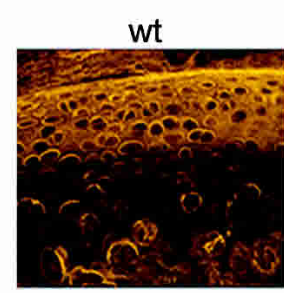

$\mathbf{F}$

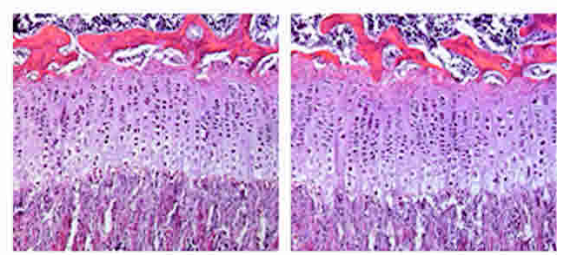

G

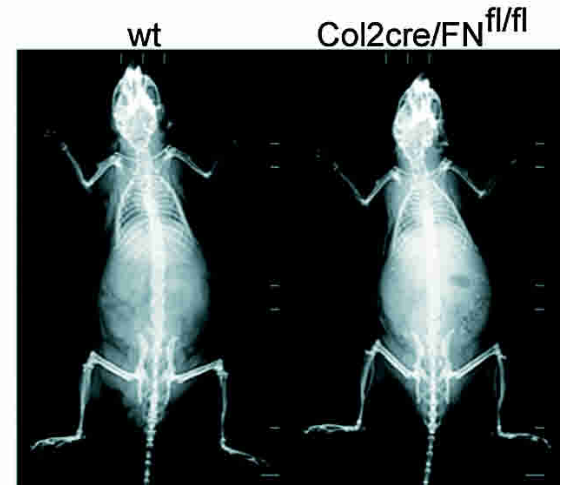

Figure 4. Organization of the collagen network is dependent on $\beta 1$ integrins. $(A-D)$ Electron micrographs of the cartilage matrix compartments of normal and mutant growth plates. $(A, B)$ Reduced collagen fibrillar density in the interterritorial matrix $(A)$ and in the territorial/pericellular compartments $(B)$ of the mutant proliferative zone at the newborn stage. (C) At 6 wk, areas with sparse and disorganized collagen fibril networks were frequently found in the proliferative zone. $(D)$ Note the fibrils with abnormally large diameters in the resting zone of mutant tissue. $(E-G)$ Normal skeletal development of mice with deleted fibronectin gene in cartilage. $(E)$ Immunostaining demonstrates the lack of fibronectin in the matrix of Col2a1-cre/FN ${ }^{f 1 / f 1}$ mice at $4 \mathrm{wk}$ of age. $(F)$ Hematoxilin-ChromotropIIR staining indicates normal growth plate structure in mutant mice. (G) X-ray analysis of 9-month-old mice demonstrated a normal skeleton in the mutant. 
matrilin-1 (Fig. 5A; data not shown) revealed no obvious abnormalities in mutant cartilage. Similarly, the distribution of other cartilage matrix proteins such as aggrecan and tenascin-C was not altered (data not shown). However, we found that the deposition of type X collagen, which is normally expressed in the hypertrophic and prehypertrophic zones, extended deeper into the proliferative zone of mutant cartilage (Fig. 5A).

In situ hybridization for chondrocyte differentiation markers at E17.5 (Fig. 5B) revealed strong Col2a1 mRNA expression in the proliferative and prehypertrophic zones of growth plates from mutant and wild-type mice. The expression of Col10a1 was defined to the hypertrophic and prehypertrophic zones in both wild type and mutant. However, the length of the hypertrophic zone was reduced and the length of the prehypertrophic zone was increased in mutant growth plates (Fig. 5B). Compared with wild type, hybridization of mutant growth plate tissue with the prehypertrophic markers Indian hedgehog (Ihh) and Parathyroid hormone/Parathyroid hormone-related peptide receptor $(P p r)$ also revealed a broadened and disorganized prehypertrophic zone, which contained fewer chondrocytes (Fig. 5B).

Next, we investigated the cartilage-bone transition and the vascular invasion front using immunohistochemical staining for gelatinase B (MMP9) and the endothelial cell surface marker endomucin, respectively. Normal MMP9 deposition was observed at the transverse septae of the cartilage-bone junction and the trabecular bone surfaces in mutants (data not shown). The vasculature in mutants was also indistinguishable from controls demonstrating normal vascular invasion into the terminal hypertrophic chondrocyte zone (data not shown). Finally, staining for alkaline phosphatase and
A
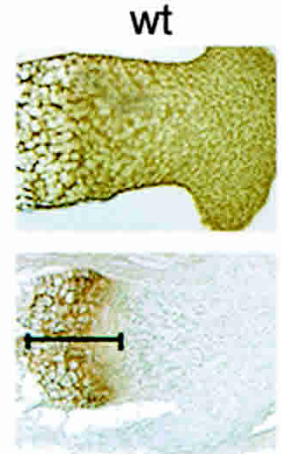

B

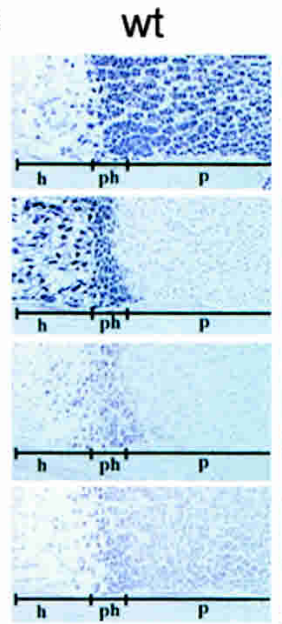

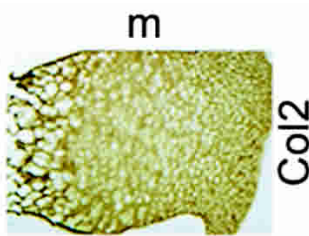

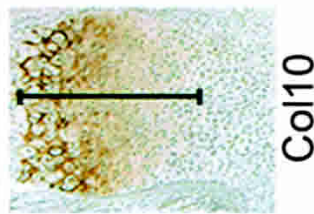

$\mathrm{m}$

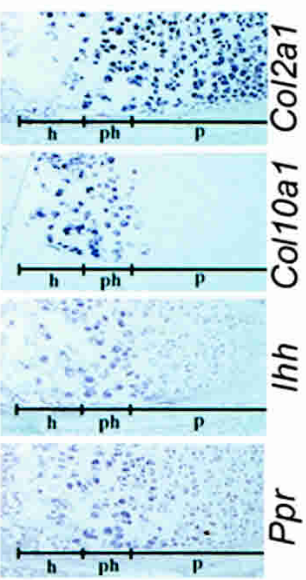

C
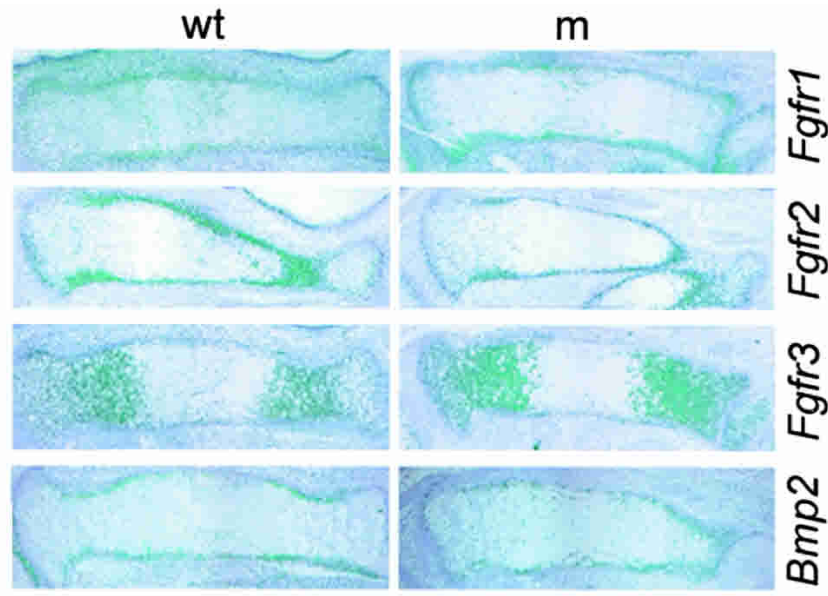

D

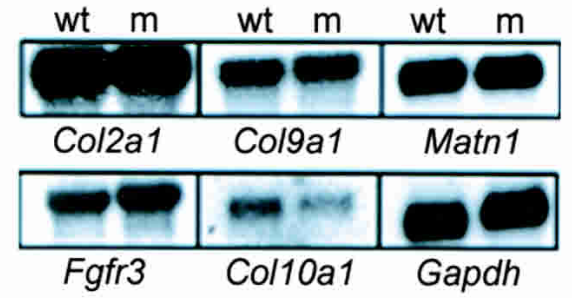

Figure 5. Analysis of the differentiation events of long bone development. (A) Immunostaining of tibia for collagen type II (Col2) and collagen type X (Col10) at E17.5. The deposition of type X collagen, a marker for hypertrophic and prehypertrophic chondrocytes, was extended into the proliferative zone of the mutant growth plate. (B) In situ hybridization for collagen II (Col2a1), collagen X (Col10a1), Indian hedgehog $(\mathrm{Ihh})$, and PTH/PTHrP receptor (Ppr). In wild type, Col2a1 was strongly expressed in the proliferative (p) and prehypertrophic (ph) zones and to lesser extent in the hypertrophic zone (h), Col10a1 in the hypertrophic and prehypertrophic zone, and $I h h$ and $P P-R$ in the prehypertrophic zone. In the mutant, the expression of Col2a1 was normal, whereas the expression domain of Col10a1 was reduced in the hypertrophic zone and broadened in the prehypertrophic zone. The expression of $I h h$ and $P P-R$ was also broadened in the prehypertrophic zone. (C) Expression of Fgfr1-3 and Bmp2 in tibia at E15.5. Whereas expression of Fgfr1, Fgfr2, and $B m p 2$ was normal, the expression of Fgfr3 was up-regulated in mutant cartilage. $(D)$ Northern blot hybridization of total RNAs derived from primary chondrocytes isolated from E17.5 limb cartilage. Expression of Col2a1, Col9a1, and matrilin1 (Matn1) was not altered in mutant chondrocytes. The expression of Fgfr3 was increased, whereas the expression of Col10a1 was decreased in mutant chondrocytes. 
tartrate-resistant acid phosphatase activity showed normal numbers of osteoblasts and osteoclasts, respectively (data not shown).

Endochondral bone formation is regulated by various signaling molecules including members of the fibroblast growth factor (FGF) and bone morphogenetic protein (BMP) family (for review, see Karsenty and Wagner 2002). To test whether the expression of Fgf receptor 1-3, $B m p 2$, and $B m p 4$ is affected by the absence of $\beta 1$ integrins, we performed in situ hybridization of E15.5 tibial sections using specific mRNA probes. Expression of Fgfr2, Bmp2, and Bmp4 in perichondrial cells was indistinguishable between wild-type and mutant tissues (Fig. 5C; data not shown). Similarly, Fgfr1 was expressed at normal level in the perichondrium and the hypertrophic chondrocytes of mutant mice (Fig. 5C). Surprisingly, however, in all tissue samples analyzed, we found an elevated Fgfr3 expression in mutant cartilage (Fig. 5C). This observation was further confirmed by Northern blot hybridization of mRNA derived from E17.5 primary chondrocytes (Fig. 5D). The expression of Col2a1, Col9a1, and Matn1 was unchanged in the mutant RNA samples (Fig. 5D), whereas the expression of Col10a1 was reduced, which is in line with the smaller hypertrophic zone in mutant growth plates (Fig. 5D).

\section{Progressive reduction of chondrocyte proliferation and increased apoptosis}

To test whether the reduced size of cartilage elements and the increased Fgfr3 expression is associated with reduced proliferation and/or survival of chondrocytes, we performed bromodeoxyuridine (BrdU) incorporation, cell cycle, and apoptosis assays at various stages of development. Using BrdU analysis (Fig. 6A), we found similar numbers of proliferating chondrocytes in control and mutant growth plates at E14.5. At later stages, we observed a gradually increasing reduction in the percentage of BrdU-positive cells in the proliferative zone of mutant tibiae. The reduction was $\cong 25 \%$ at the newborn stage and $\cong 60 \%$ at 3 wk of age. At 6 wk of age, the mutant growth plates almost completely lacked proliferative cells.

The analysis of the cell cycle by immunohistochemistry for D-type cyclins (cyclins D1, D2, and D3), which control G1 progression, revealed a progressive proliferation defect, although less severe than observed with the BrdU incorporation assay (Fig. 6B). Cyclin-D-positive cells were reduced in the mutant growth plate by $10 \%$ at the newborn stage and by $20 \%$ at 3 wk of age compared with controls. At $6 \mathrm{wk}$, cyclin-D-positive cells were
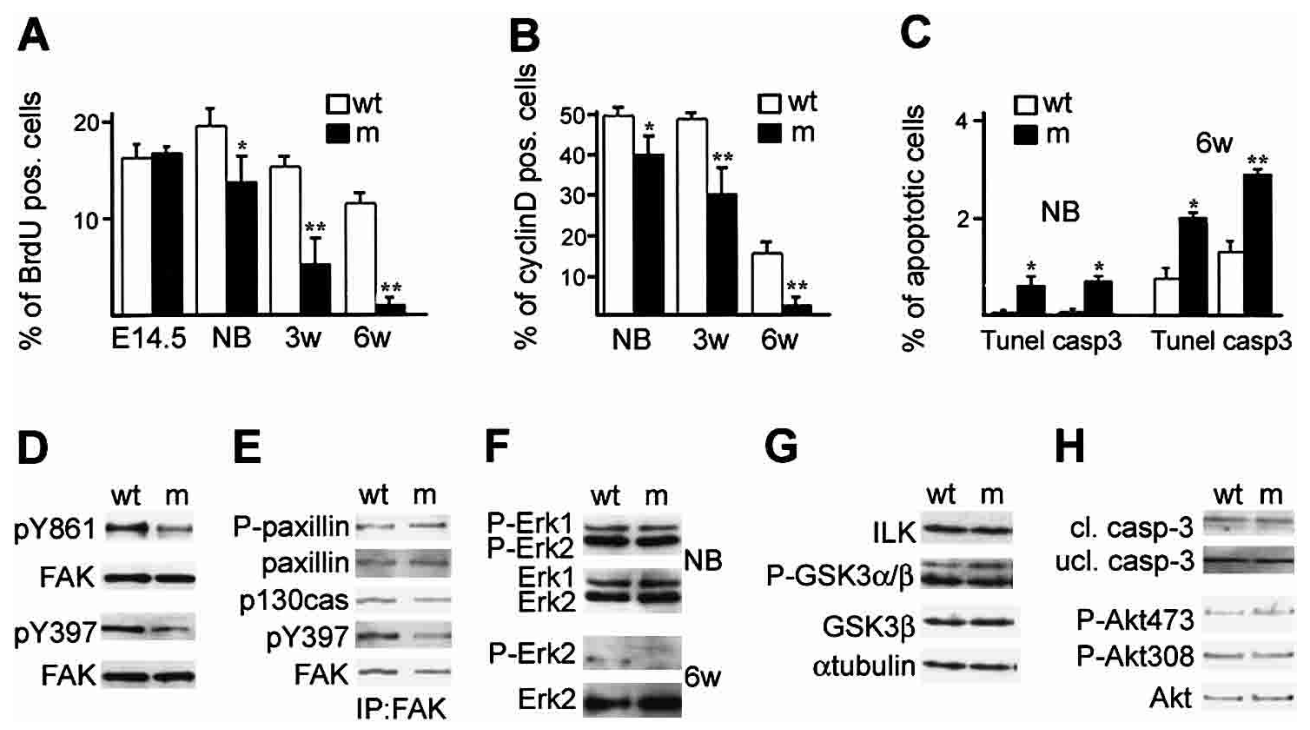

Figure 6. Analyses of chondrocyte proliferation and apoptosis in wild-type (wt) and mutant $(\mathrm{m})$ mice. $(A)$ Analysis of chondrocyte proliferation by BrdU incorporation assay. The diagram shows a progressive reduction of BrdU-labeled nuclei from E14.5 to 6 wk of age. Error bars represent S.D. Asterisks indicate a statistically significant difference between control and wild type ${ }^{\star}, P<0.05 ;{ }^{\star}$, $P<0.01)$. (B) Diagram showing the percentage of cyclin-D-positive cells in wild-type and mutant growth plates assessed by immunostaining at various stages. $(C)$ Diagram showing the percentage of TUNEL and cleaved caspase-3 (cl. casp-3) positive chondrocytes in newborn and 6-week-old tibias. $(D)$ Western blotting demonstrated decreased tyrosine phosphorylation level of FAK at the tyrosine residues $861\left(\mathrm{pY}^{861}\right)$ and $397\left(\mathrm{pY}^{397}\right)$. The blot was reprobed for total FAK. (E) Reduced FAK activation was not associated with decreased recruitment of p130cas and paxilin. FAK immunoprecipitates were analyzed by Western blotting with antibodies against FAK, FAK Tyr 397 (pY397), p130cas, paxillin, and phospho-paxillin (p-paxillin). (F) Western blot analysis of MAP-kinases activity. The levels of phosphorylated Erk1 and Erk2 were apparently normal at the newborn stage in mutant cells. At 6 wk, phospho-Erk2 was detected in wild-type but not in mutant samples. The blots were reprobed for total Erk. $(G)$ Analysis of the expression level of ILK and the phosphorylated form of GSK3 $\alpha / \beta$. The levels of ILK and phospho-GSK3 $\alpha / \beta$ were normal in the mutant. $(H)$ Biochemical analysis of apoptosis in newborn primary chondrocytes. The level of cleaved caspase-3 (cl. casp-3; upper panel) and the levels of phosphorylated Akt Thr 308 and Ser 473 (lower panel) were not significantly different in the mutant compared with wild type. The blots were reprobed for uncleaved caspase-3 (ucl. casp-3) and total Akt. 
hardly detectable in the mutant growth plate. The reduction of cyclin D expression was also confirmed by Western blotting of extract of newborn primary chondrocytes, whereas the level of M-type cyclins (cyclin A and B) did not change significantly (data not shown), suggesting a delayed G1/S transition.

Progression through the G1 phase and the G1/S transition check point is achieved by the activity of cyclindependent kinases (CDKs) and negatively regulated by CDK inhibitors (CKIs). Chondrocytes express several CKIs belonging to the Cip/Kip (p21 $1^{\text {Cip1 }}, \mathrm{p} 27^{\text {Kip } 1}, \mathrm{p} 57^{\text {Kip2 }}$ ) or the Ink4 (p16 $\left.{ }^{\text {Ink4a }}, \mathrm{p} 18^{\text {Ink4c }}, \mathrm{p}^{\text {Ink }}{ }^{\text {Ind }}\right)$ family (Beier et al. 1999), and some of them become activated by Fgfr3 signals (Su et al. 1997; Li et al. 1999). Therefore, we analyzed the expression of p16, p21, p27, and p57 on E17.5 wild-type and mutant long bones (Fig. 7A). In wild type, all CKIs were strongly expressed in the prehypertrophic and hypertrophic zones containing postmitotic, differentiated chondrocytes, whereas the expression was low in the proliferative zone containing cycling cells. Although $\beta 1$-null growth plates revealed normal p27 and p57 expression, the number of p16- and p21-positive cells was significantly increased (Fig. 7A,B). The labeling index for p16 (the number of positive cells correlated to the total number of cells) was $14 \% \pm 3.4 \%$ in control and $32 \% \pm 2.8 \%$ in mutant. The labeling index for p21 in control and mutant proliferative zone was $11 \% \pm 2.6 \%$ and $18.5 \% \pm 3.1 \%$, respectively (Fig. $7 \mathrm{~B}$ ). Interestingly, this increase was restricted to the proliferative zone and not observed in the epiphyseal cartilage (Fig. 7B).

Several reports demonstrated that elevated FGF signaling promotes nuclear translocation of Stat1 (signal transducers and activators of transcription 1) and Stat5a/ Stat5b, which in turn up-regulate CKIs including p16 and p21 (for review, see Ornitz and Marie 2002). To test whether Stat protein translocation is increased in $\beta 1$ null growth plates, we performed Stat 1 and Stat5a immunostaining. Whereas Stat 1 expression was faint and localized to the cytoplasm in wild-type proliferative chondrocytes (Fig. 7C), cytoplasmic staining was increased in mutant growth plates, and several chondrocytes displayed clear nuclear staining (Fig. 7C). In addition, $10.5 \% \pm 2.8 \%$ wild-type chondrocytes showed nuclear translocation of Stat5a1. This value increased to $17 \% \pm 3.2 \%$ in mutant chondrocytes (Fig. 7C).

To investigate whether other $\beta 1$-integrin-dependent signaling pathways also contribute to the defective chondrocyte proliferation, we isolated primary chondrocytes and analyzed the activity of signaling molecules. Immunoblotting with antibodies that recognize focal adhesion kinase (FAK) phosphorylated at specific tyrosine residues $\left(\mathrm{pY}^{861}\right.$ and $\left.\mathrm{pY}^{397}\right)$ demonstrated significantly decreased FAK activation in mutant samples already in newborns (Fig. 6D). Surprisingly, the decreased phosphorylation of FAK was not associated with the reduced recruitment of p130Cas or paxillin to FAK (Fig. 6E), suggesting that the downstream pathways mediated by p130Cas and paxillin are not affected in $\beta 1$-integrin-deficient chondrocytes. Western blot assays with antibodies against extracellular signal-regulated kinases (Erk1 and Erk2) revealed no ap-
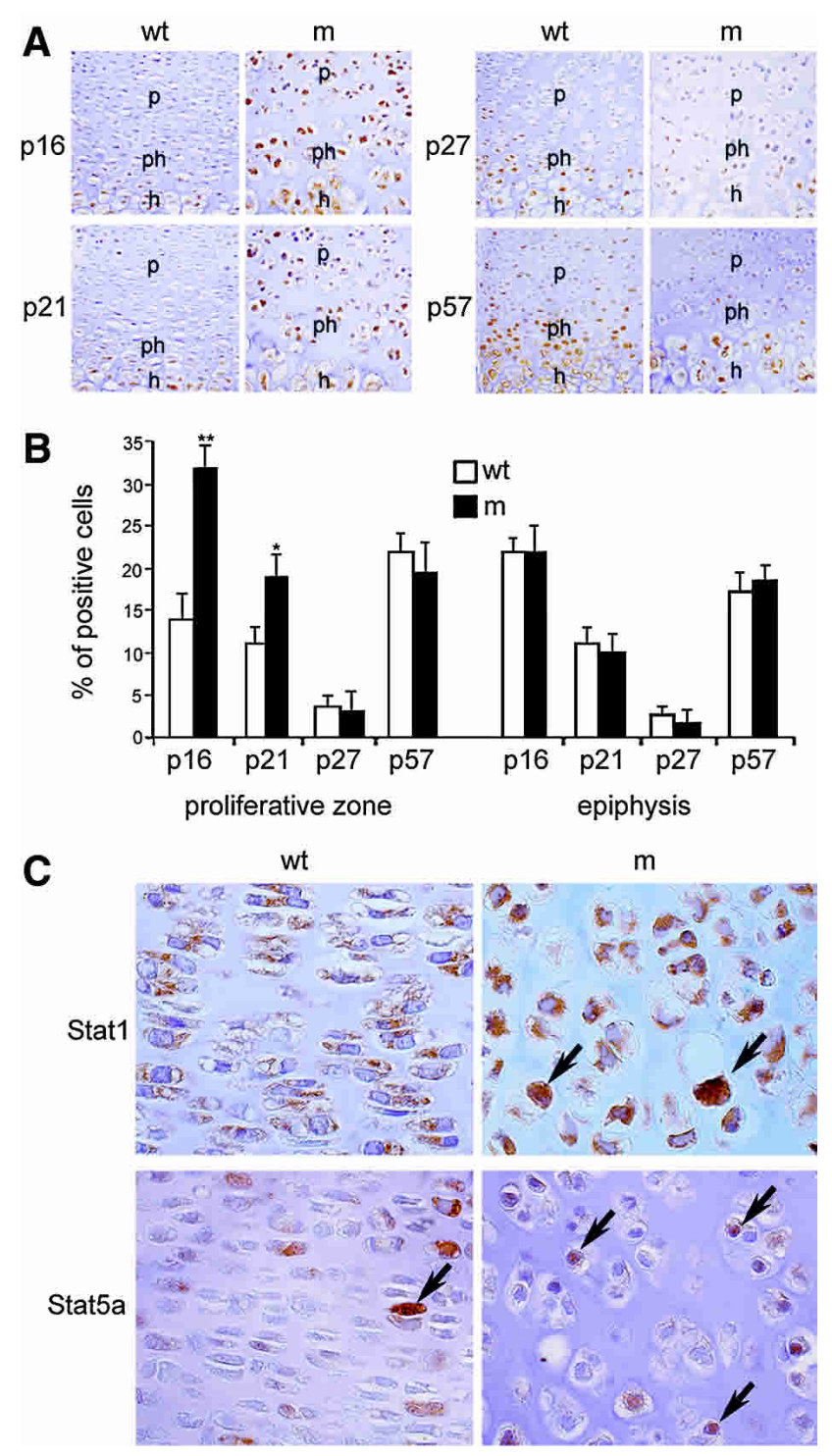

Figure 7. Increased expression of the cell cycle inhibitor p16 and $\mathrm{p} 21$ and nuclear translocation of Stat 1 and Stat5a in $\beta 1$-null proliferative chondrocytes. (A) Immunohistochemistry for cell cycle inhibitors in E17.5 wild-type (wt) and mutant $(\mathrm{m})$ growth plates. The expression of p16 and p 21 was selectively increased in the mutant proliferative zone $(\mathrm{p})$, whereas the expression of p27 and 57 was similar as in wild type. (ph) Prehypertophic zone; (h) hypertrophic zone. $(B)$ Diagram showing the percentage of cell-cycle-inhibitor-positive cells in the proliferative zone of the growth plate and in the epiphyseal cartilage. Error bars represent S.D. Asterisks indicate a statistically significant difference between control and wild type $\left({ }^{\star}, P<0.05{ }^{\star \star}{ }^{\star}, P<0.01\right)$. $(C)$ Immunostaining for Stat 1 and Stat5a indicates increased nuclear translocation (arrows) in the mutant proliferative zone.

parent difference in their activation state at the newborn stage. At 6 wk, however, activated Erk2 was detected in wild-type, but not in mutant samples (Fig. 6F).

Integrin-linked kinase (ILK) was shown to associate with the $\beta 1$ integrin cytoplasmic domain, and mice with a cartilage-specific $I L K$ gene deletion also display re- 
duced chondrocyte proliferation characterized by a defective G1/S transition (Grashoff et al. 2003). To test whether ILK function is changed in $\beta 1$-null chondrocytes, we analyzed ILK expression and the phosphorylation state of glycogen synthase kinase 3- $\beta$ (GSK3b) and protein kinase $\mathrm{B} / \mathrm{Akt}(\mathrm{Akt})$, two debated target proteins suggested to be modified by the kinase activity of ILK (Brakebusch and Fässler 2003). We found similar levels of ILK in control and mutant extracts (Fig. 6G). Moreover, mutant chondrocytes showed normal phosphorylation of GSK3- $\beta$ (Fig. 6G) and Akt (Fig. 6H).

Cell death was analyzed on tissue sections using the TUNEL (terminal deoxynucleotidyl transferase mediated dUTP nick end labeling) assay and immunostaining for cleaved caspase-3 (Fig. 6C). Apoptotic cells were found at the forming joint surface and at the chondroosseous junction of the tibia from E17.5 control mice (data not shown). In mutants, areas with TUNEL or cleaved caspase-3-positive cells were found in epiphyseal as well as growth plate cartilage (data not shown), although the number of apoptotic cells was below $1 \%$ (Fig. 6C). At 6 wk, apoptotic chondrocytes were detected by TUNEL and caspase- 3 immunostaining throughout the mutant growth plate, and their number increased to $3 \%$ (Fig. 6C). Consistent with the very low apoptotic rate observed in tissue sections, we found no elevated activation of the apoptosis marker caspase- 3 in mutant cell extracts compared with control (Fig. 6H).

\section{Defect in cytokinesis in the absence} of $\beta 1$ integrin expression

Despite the defect in the G1/S transition, the analysis of DNA content of primary newborn chondrocytes by FACS indicated an increased number of G2/M $16 \%$ increment) and a decreased number of G0/G1 cells (14\% reduction) in mutant mice compared with wild type (Fig. $8 \mathrm{~A})$. The accumulation of chondrocytes in the G2/M phase together with the presence of binucleate cells in mutant growth plates suggest a defect in cytokinesis. To further investigate the defect, we analyzed the morphology and nuclei profile of chondrocytes at the ultrastructural level. The size of the newborn mutant cells was increased in each zone of the growth plate, and the shape of proliferative chondrocytes was spherical instead of flattened (Fig. 8B). The nuclei of mutant chondrocytes were abnormal in shape and had intensely stained heterochromatic areas (Fig. 8B). The number of multinucleate chondrocytes was $<0.2 \%$ in wild type, whereas in mutants it was between $4 \%$ and $8 \%$ depending on the growth plate zonality (Fig. 8B,C). Most of them were binucleate (Fig. 8B), but occasionally chondrocytes with three or four nuclei were also observed. The frequency of binucleate cells increased with age in mutants. In 6-week-old growth plates, we found $\sim 30 \%$ of cells with two nuclei in mutant tissue, whereas in control sections the percentage of binucleate chondrocytes was $<1 \%$. Altogether, these data suggest that cytokinesis is impaired in $\beta 1$-integrin-deficient chondrocytes.

Cell division requires the temporary assembly of an
F-actin/myosin contractile system, called the cleavage furrow, that contains numerous other proteins including $\alpha$-actinin and talin (Fujiwara et al. 1978; BellissentWaydelich et al. 1999), which can directly bind the cytoplasmic tail of the $\beta 1$ integrin. To test whether $\beta 1$ integrin is located in the cleavage furrow, where it could contribute to cell division, we performed double staining with FITC-phalloidin and anti- $\beta 1$ integrin antibody on cultured wild-type chondrocytes. During prophase, when chromatin condenses into chromosomes; during metaphase, when chromosomes align along the equatorial plane; and during early anaphase, when chromatids separate and the chromosomes move to opposite spindle poles; $\beta 1$ integrin was detected at FA similarly to the interphase cell (data not shown). In late anaphase and telophase, when the actomyosin contractile ring forms, the cleavage furrow was intensively stained for both phalloidin and $\beta 1$ integrin (Fig. 8D).

\section{Discussion}

Following each division, chondrocytes migrate apart from each other and occupy separate lacunae, which contain a large number of ECM proteins. Here, they form numerous cell-matrix interactions, which are mainly mediated by integrins. In the present paper, we report that a Cre/lox $P$-mediated deletion of the $\beta 1$ integrin gene in chondrocytes results in a severe chondrodysplasia with a high rate of perinatal lethality. The chondrodysplasia progresses after birth and is characterized by a distorted growth plate containing misshaped chondrocytes, which fail to arrange into columns, a reduced cell number, and an abnormal network of collagen fibrils. The decreased proliferation was associated with defective G1 progression as well as cytokinesis.

\section{$\beta 1$ integrin-ECM interactions are essential for the growth plate structure}

The deletion of the $\beta 1$ integrin gene in sclerotomal cells affected neither their migration to the perinotochordal area, nor their condensation and subsequent differentiation into vertebral chondrocytes, suggesting that $\beta 1$-integrin-mediated cell-matrix interactions are either not essential for these processes or are efficiently compensated by other cell adhesion molecules.

It has been reported previously that anti- $\beta 1$ integrin antibodies perturb condensation and differentiation of cultured limb bud mesenchyme into chondroblasts (Shakibaei 1998). Because we observed still faint $\beta 1$ expression during the formation of the cartilaginous anlage of the long bones, we cannot exclude the possibility that $\beta 1$ integrins are important for the initial differentiation of the appendicular skeleton.

Chondroblast differentiation is followed by the formation of ossification centers and growth plates. The primary ossification center in the diaphysis, and the secondary ossification centers in the epiphysis are formed, but significantly delayed in the absence of $\beta 1$ expression. 
Aszodi et al.

A

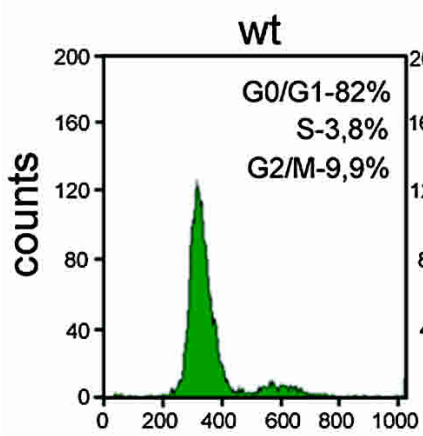

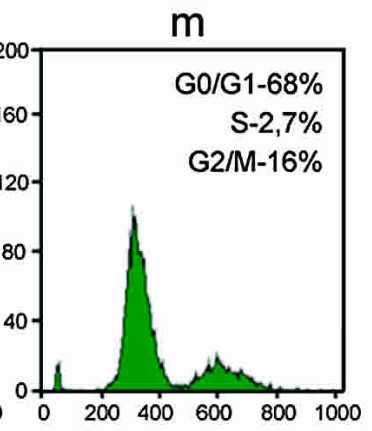

$\mathrm{FL}$
B

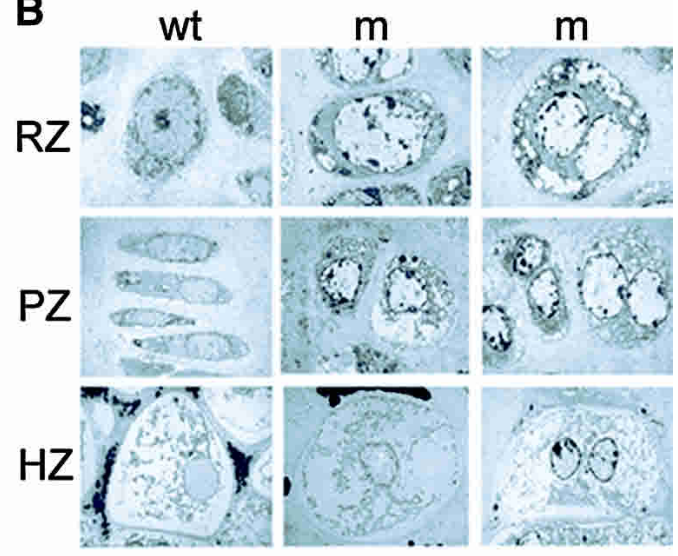

\section{C}
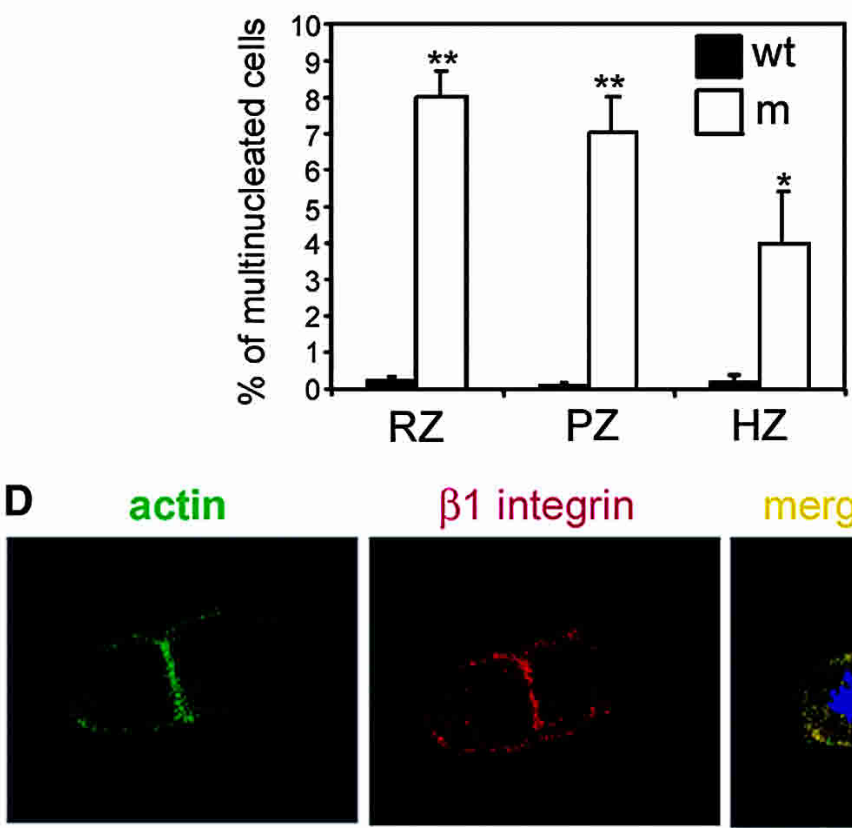

merged+dapi


Figure 8. $\beta 1$-integrin-deficient chondrocytes accumulate in the G2/M phase and show a high rate of binucleation. $(A)$ FACS analysis of cell cycle distribution of newborn wild-type and mutant primary chondrocytes. $(B)$ Electron micrographs showing chondrocyte morphology in the resting (RZ), proliferative (PZ), and hypertrophic (HZ) zones of the growth plate of wild-type (wt) and mutant (m) tibia at E17.5. Note the round shape and increased size of chondrocytes in each zone of the mutant growth plate. Mutant cells had decreased euchromatin and frequently showed binucleation. $(C)$ Diagram showing the percentage of multinucleate chondrocytes in the zones of wild-type and mutant cartilage at E17.5. Error bars represent S.D. ( $\left.{ }^{\star}, P<0.05 ;^{\star \star}, P<0.0001\right)$. $(D)$ Localization of $\beta 1$ integrin in the cleavage furrow. Dividing wild-type primary chondrocytes were immunostained for actin and $\beta 1$ integrin. DNA was visualized with DAPI staining.

The cause for the delay is unclear. A possible explanation is an abnormal deposition of matrix proteins and a delay in hypertrophy, similar to what we observed in growth plates. Growth plates form on both ends of long bones and are responsible for endochondral ossification. Their chondrocytes are arranged into columns and become greatly enlarged, or hypertrophic, just in advance of the marrow, where the cartilage is removed and bone 
deposited. These columns originate from single, rounded chondrocytes in the resting zone (Doods 1930). Cell division of chondrocytes occurs perpendicular to the long axis of the bone. The daughter cells then flatten and move to form a cell stack parallel to the long axis of the bone (see Supplementary Video 1). These stacks of flattened cells are elongated by repeated cell divisions in the proliferative zone. In $\beta 1$-null growth plates, proliferative chondrocytes did not flatten and were still large and round. Although their mitotic figures were still perpendicular to the long axis, no shape change and only partial movements occurred. Therefore, the mutant chondrocytes did not arrange into columns leading to broadened bones and preventing the formation of defined longitudinal septae between the columns (see Supplementary Video 2). Consequently, the mineralization of the matrix in the hypertrophic zone and the formation of trabecular bones were severely impaired in the mutants.

The abnormal chondrocyte shape and their impaired movement to form columns could most simply be explained by insufficient adhesion of the $\beta 1$-null chondrocytes to the surrounding matrix, which is essential for all types of shape changes. Indeed, $\beta 1$-integrin-deficient chondrocytes isolated from newborn mice failed to adhere to collagen II and laminin-1 and adhered 50\% less efficiently to fibronectin than wild-type cells. Conceivably, also the attachment to other abundant cartilage proteins such as perlecan, matrilin-1, and chondroadherin, which bind to $\beta 1$ integrins, is lost or reduced.

Alternatively, or in addition, loss of integrin signaling could contribute to the phenotype. Integrin-matrix interactions modulate the activity of members of the Rho family of GTPases that, in turn, rearrange the cytoskeleton. Indeed, we found a disorganization of the actin network in mutant chondrocytes in vivo, whereas the intermediate filament and microtubule systems showed no apparent alterations. In wild-type cells, the actin was evenly localized beneath the plasma membrane, whereas in many mutant chondrocytes, the actin distribution was more punctuated. When we isolated normal and mutant chondrocytes and plated them on FN, we observed a severe defect in spreading and a reduced formation of stress fibers and fewer and smaller focal contacts, suggesting that actin rearrangements and FA formation are severely disturbed in the absence of $\beta 1$ integrin. Mutant primary chondrocytes showed a significantly reduced activation of FAK, which is known to activate Racl via Cas/Crk, paxillin, or PI3-K (for review, see Parsons et al. 2000). Because the amounts of FAK-associated Cas and paxillin were normal, these pathways seem not to be integrin-dependent in chondrocytes in vivo. Owing to the limited amount of chondrocytes obtained from rib cages of newborn mice, it was not possible to assess the activity of Rac1.

\section{Do $\beta 1$ integrins modulate chondrocyte differentiation?}

It has been reported that anti- $\beta 1$ integrin antibodies block the deposition of type $\mathrm{X}$ collagen in chicken sternal organ culture, suggesting that the terminal differen- tiation of chondrocytes is mediated by integrin $\beta 1$ family members (Hirsch at al. 1997). We found a reduced but not a complete block of collagen type X expression. In addition, we observed shorter hypertrophic zones and larger prehypertrophic zones in mutant growth plate, suggesting a complex role of $\beta 1$ integrins in chondrocyte maturation and hypertrophy.

The regulation of chondrocyte differentiation in the growth plate is largely unknown, but pathways via Ihh/ PTHrP signaling clearly play a role (Lanske et al. 1996; Vortkamp et al. 1996; St-Jacques et al. 1999). In the fully developed growth plate, Ihh is produced by prehypertrophic chondrocytes and induces the expression of PTHrP by periarticular cells. PTHrP diffuses from the articular ends and acts on the PTH/PTHrP receptor (PPR), which is expressed throughout the growth plate, reaching the highest level in the prehypertrophic zone, and prevents hypertrophy. We found that in the mutant growth plate, both Ihh and Ppr demarcate a broader prehypertrophic zone with fewer cells compared with wild type. This observation suggests that chondrocyte maturation is perturbed, which might in part account for the reduced length of the hypertophic zone in the mutant growth plate. However, how $\beta 1$ integrins are involved in differentiation is unclear. The absence of $\beta 1$ integrin-matrix interactions might directly modulate chondrocyte differentiation, or these changes could also be an indirect consequence of the structural disorganization of the mutant growth plate.

Additional signaling pathways controlling chondrocyte hypertrophy can also emerge from the perichondrium. These pathways include FGFs, BMPs, TGFßs, and their receptors (for review, see Karsenty and Wagner 2002; Vortkamp 2001). Although the $\beta 1$ integrin gene is deleted in perichondrial cells, the expression of Fgfr1, Fgfr2, Bmp2, and Bmp4 was unaffected, suggesting no obvious role of $\beta 1$ integrins for the expression of these perichondrial markers.

\section{$\beta 1$ integrins control G1/S transition through Fgfr3}

Integrin signaling plays an important role in the control of cell growth. $\beta 1$-deficient chondrocytes showed a reduced proliferation in vivo that became more severe after birth. This impaired proliferation correlated well with a reduced activation of Erk and a diminished expression of cyclin $\mathrm{D}$, suggesting impaired G1/S transition in the cell cycle. Several of our observations could contribute to this G1 cell cycle defect. First, reduced activation of FAK might contribute to the reduced Erk phosphorylation and diminish chondrocyte growth.

Second, Ihh is another important player that, in addition to its prominent role during chondrocyte differentiation, can regulate chondrocyte proliferation. Ihh was shown to diffuse from the prehypertrophic zone into the proliferative zone (Gritly-Linde et al. 2001), where it supports chondrocyte proliferation at least in part by modulating cyclin D1 expression (St-Jacques et al. 1999; Long et al. 2001). We found that the zone of Ihh expression is disorganized and contains fewer cells in the mutant 
growth plates. It is possible that the gradual increase of the extracellular space with age is causing impaired Ihh diffusion leading to impaired Ihh signaling, reduced cyclin D1 expression, and as a consequence, decreased chondrocyte proliferation. Alternatively, Ihh signaling might depend on intact $\beta 1$ integrin signals as shown for Shh in neuronal cells (Pons et al. 2001).

Third, multiple growth factor signaling cascades depend on integrin activity in a variety of cell types. A candidate growth factor for such a cooperativity is FGF, which signals through FGFR3 and negatively regulates chondrocyte proliferation during endochondral bone formation (for review, see Karsenty and Wagner 2002; Ornitz and Marie 2002). Constitutive active Fgfr3 mutations lead to dwarfing dysplasias such as hypochondroplasia, achondroplasia (ACH), and thanatophoric dysplasia (TD) in humans and a transgene with the $\mathrm{ACH}$ mutation results in a similar defect in mice. Moreover, chondrocytes from TD patients and transgenic mice expressing the activated form of Fgfr3 activate Stat proteins (Stat1, Stat5a, and Stat5b) and up-regulate the expression of cell cycle inhibitors p16, p18, p19, and p21 (Su et al. 1997; Li et al. 1999). We tested the expression levels of Fgfr3 in $\beta 1$ mutant growth plates and primary chondrocytes and found significantly elevated levels of Fgfr3. This rise of Fgfr3 was associated with increased nuclear translocation of Stat1/Stat5a and expression of p16 and p21 in the proliferative zone of $\beta 1$-null growth plates. These data show for the first time that $\beta 1$ integrin crosstalks to Fgfr3 by regulating Fgfr3 mRNA levels in normal chondrocytes either by repressing Fgfr3 transcription or by reducing the stability of Fgfr3 mRNA.

Finally, a chondrocyte-specific deletion of ILK, which may bind the $\beta 1$ integrin cytoplasmic domain, leads to pronounced proliferation defects, reduced cyclin D levels, abnormal F-actin distribution, and changes in cell shape (Grashoff et al. 2003). Although these defects are also observed in $\beta 1$-null growth plates, several key findings suggest that ILK activity and ILK-mediated signaling is, if at all, mildly affected by the loss of $\beta 1$ expression. $\beta 1$-null chondrocytes have normal ILK levels, and newborn ILK-null chondrocytes have normal expression of integrins, Ihh, and Fgfr3 (Grashoff et al. 2003; A. Aszodi, C. Grashoff, and R. Fässler, unpubl.). Furthermore, ILK-null chondrocytes have a very mild integrinmediated adhesion defect, and their ability to arrange into columns is only slightly diminished (Grashoff et al. 2003).

\section{$\beta 1$ integrins regulate cytokinesis of chondrocytes and their survival}

A second abnormality of the cell cycle occurs during the M-phase. Already during embryogenesis, the percentage of binucleate cells increased significantly, suggesting either a prolonged or an aborted cytokinesis. The percentage of binucleate chondrocytes increased further after birth, reaching $30 \%$ of the cells in 6 -week-old mice. Conceivably, both the progressive loss of cyclin D expression and the defective cytokinesis contribute to the almost complete abolishment of chondrocyte proliferation in 6-week-old mutant mice.

The impaired cytokinesis in the absence of $\beta 1$ integrin seems to be a chondrocyte-specific defect because we did not observe binucleate cells in other $\beta 1$-deficient cell types such as ES cells, fibroblasts, keratinocytes, or hematopoietic cells. It could be that the furrow formation between the dividing cells is more dependent on $\beta 1$ integrin in chondrocytes than in other cell types. The furrow was shown to contain an increased amount of integrin-associated, actin-binding proteins such as $\alpha$-actinin (Fujiwara et al. 1978) and talin (Bellissent-Waydelich et al. 1999). We could demonstrate that $\beta 1$ integrin subunits localize to the cleavage furrow of dividing chondrocytes, where they might either help to anchor the F-actin ring to the membrane or alternatively induce contraction to complete cell division. In cells other than chondrocytes, this anchoring function may depend for example more on ERM (ezrin-radixin-moesin) proteins, which are also enriched in the cleavage furrow (Sato et al. 1991).

In addition to the defect in proliferation, we found a slight, but significant increase in the apoptotic rate, suggesting that $\beta 1$-integrin-mediated collagen-chondrocyte interactions support chondrocyte survival. This finding is in line with previous observations. First, anti- $\beta 1$ blocking antibodies increase death of sternal chondrocytes in an organoid culture system (Hirsch et al. 1997). Second, collagenase treatment of suspended chondrocyte cultures increases apoptosis, whereas readdition of collagen type I to the collagenase-digested cultures prevents apoptosis (Cao et al. 1999). Finally, the absence of collagen II expression in cartilage in vivo is also associated with an increase of apoptotic chondrocytes (Yang et al. 1997). Integrins can inhibit programmed cell death by activation of Erk, the FAK-Rac1-JNK pathway, or activation of Akt through FAK and PI3K /Giancotti and Rouslahti 1999). In $\beta 1$-deficient chondrocytes, we observed no change in Akt activation, but reduced amounts of phosphorylated Erk and FAK, suggesting that the latter two signaling pathways are most likely contributing to the increase in apoptosis.

\section{Collagen-binding integrins regulate assembly of type II collagen network}

Loss of $\beta 1$ integrin expression in cartilage leads to ultrastructural abnormalities of the fibrillar collagen network. In addition to a general reduction of fibril density in the mutant matrix, we found striking changes in the structure of collagen fibrils. Fibrils were of irregular diameter, sometimes even 10 -fold thicker than normal. Because $\beta 1$-null chondrocytes failed to adhere to collagen II in vitro, the disordered collagen fibrillar network seems to occur independently of collagen binding to cellular receptors. However, it indicates that $\beta 1$ integrin expression on chondrocytes is essential for the formation of a typical collagen fibrillar network.

Collagen can bind fibronectin, and several reports suggest that the fibronectin network functions as a scaffold 
for the newly generated collagen fibrils (Hedman et al. 1982; Velling et al. 2002). However, the normal phenotype of the cartilage in mice with a cartilage-specific deletion of the fibronectin gene strongly argues against this hypothesis. In addition, the fibronectin-deficient mice demonstrate that chondrocyte attachment to FN mediated by $\alpha 5 \beta 1$ and $\alpha \mathrm{v} \beta 3$ is not essential for chondrocyte shape, motility, cytokinesis, differentiation, or survival.

The decreased density of the collagen network could be explained by several mechanisms. First, despite the normal expression level of Col2a1 mRNA, the deposition of collagen II into the matrix is decreased because of fewer cells in the mutant cartilage. Second, the abolished signaling via $\beta 1$ integrins increases the expression or the activity of matrix metalloproteases (MMPs), which de grade collagens. We observed no differences in the MMP-2, MMP-9, and MMP-13 levels in mutant and wild-type long bones, but we cannot rule out that the activity of other MMPs is altered in the absence of $\beta 1$ integrins. However, the normal vascularization at the chondro-osseous junctions and the lack of collagen fibril degradation products in the matrix argue against these hypotheses. The reduced density of collagen fibrils could result in an increased diffusion of soluble substances in the cartilage matrix of $\beta 1$-mutant mice. This might account for the unusual expansion of the type $\mathrm{X}$ collagen immunoreactivity into the proliferative zone and could also affect the function of growth factors.

\section{Materials and methods}

\section{Generation of conditional knockout mice}

Mouse strains carrying the null (Fässler and Mayer 1995) and floxed $\beta 1$ integrin (Potocnik et al. 2000) and fibronectin genes (T. Sakai et al. 2001) were described earlier. To achieve chondrocyte-specific deletion of the floxed genes, mice were crossed with transgenic mice expressing the Cre-recombinase under the control of regulatory regions of the mouse collagen type II (Col2a1) gene (K. Sakai et al. 2001).

\section{Antibodies}

For immunological studies the following antibodies were used: against collagen type II, collagen type $\mathrm{X}$, aggrecan, fibromodulin, tenascin-C, COMP (for details, see Aszodi et al. 1998); perlecan (Costell et al. 1999); matrilin-1, -2, and -3 (Aszodi et al. 1999); endomucin (Morgan et al. 1999); MMP2, MMP9, and MMP13 (obtained from Gillian Murphy, School of Biological Sciences, Norwich, England); p16, p21, p57, Stat1, and Stat5a (Santa Cruz Biotech); p27 (Cell Signaling Technology), paxillin, phospho-paxillin, p130cas (Transduction Laboratories); zyxin (obtained from Jürgen Wehland, GBF, Braunschweig, Germany); vinculin (Sigma); $\beta 1$ integrin (Brakebusch et al. 2000); and fibronectin (T. Sakai et al. 2001). Actin was detected by FITC-conjugated phalloidin (Sigma). For flow cytometry, rat monoclonal antibodies against mouse $\beta 1, \beta 3, \beta 5, \alpha 1, \alpha 2, \alpha 3, \alpha 5$, and $\alpha 6$ integrin subunits (PharMingen) were used. For protein analysis, rabbit antibodies against FAK (Santa Cruz Biotech); FAK Tyr397 and FAK Tyr861 (Biosource International); Akt, Akt Thr 308, Akt Ser 473, ERK1/2, phospho-ERK1/2, phospho-GSK3 $\alpha / \beta$, uncleaved caspase-3, cleaved caspase-3 (all from Cell Signaling
Technology); cyclin-D1, cyclin-A, cyclin-B (Upstate Biotechnology and Santa Cruz Biotech); and ILK (Transduction Laboratories) were used.

\section{Skeletal analyses}

Staining of whole embryos with alcian blue/alizarin red (Aszodi et al. 1998) and X-gal (K. Sakai et al. 2001) was described earlier. $\mathrm{X}$-ray analysis of adult mice was performed as described (Aszodi et al. 1999).

Histochemistry, immunostaining, and electron microscopy were carried out as described earlier (Aszodi et al. 1998). Apoptotic chondrocytes were detected using either the "In situ cell death detection" kit (Roche Diagnostics) or the cleaved caspase-3 immunostaining. Cell proliferation was analyzed using BrdU (5-bromo-2' -deoxyuridine) incorporation (Aszodi et al. 1998).

For Northern blot analysis, total RNA was isolated from primary rib or limb chondrocytes, gel separated, and probed with ${ }^{32} \mathrm{P}$-labeled cDNAs. Nonradioactive in situ hybridization on tissue sections for Col2a1, Col10a1, Ihh, and PTH/PTHrP receptor (Ppr) was performed as described by Brandau et al. (2002). Radioactive in situ hybridization was performed as described (Aszodi et. al. 1998) using ${ }^{33}$ P-UTP-labeled riboprobes against Fgfr1-3, Bmp2, and Bmp4.

\section{Isolation and assays with primary chondrocytes}

Chondrocytes from rib, epiphyseal, and growth plate cartilage were isolated from newborn or 6-week-old wild-type and mutant mice. Rib cages and joints were dissected in DMEM supplemented with $2 \%$ fetal calf serum (FCS) and streptomycin/penicillin. Adherent tissues and the perichondrium were physically removed after a collagenase (type II, Worthington) digestion (2 $\mathrm{mg} / \mathrm{mL}$ in DMEM $/ 2 \% \mathrm{FCS}$ ) at $37^{\circ} \mathrm{C}$ for $30 \mathrm{~min}$. Chondrocytes were released using fresh collagenase medium in a humidified atmosphere $\left(5 \% \mathrm{CO}_{2}, 95 \%\right.$ air) for $2-4 \mathrm{~h}$.

Adhesion assays with normal and mutant chondrocytes were carried out as described by Fässler et al. (1995).

For cell spreading, primary chondrocytes were seeded in DMEM supplemented with $0.5 \%$ FCS on glass 8-well Lab-Tek chamber slides (Nalge Nunc International) coated with fibronectin or vitronectin. Cells were allowed to spread for $3 \mathrm{~d}$ then subjected to antibody staining.

For flow cytometry, primary chondrocytes were incubated with primary antibodies against integrin subunits (see above), then with FITC-conjugated secondary antibodies and then analyzed for fluorescence with a FACSCAN flow cytometer (Becton Dickinson). Cell cycle analysis was performed by propidium iodine staining and FACS.

\section{Protein analysis}

Freshly isolated cartilage tissues or primary chondrocytes were homogenized in RIPA lyses buffer, incubated on ice for $30 \mathrm{~min}$, and centrifuged at $10,000 \mathrm{rpm}$ at $4^{\circ} \mathrm{C}$ for $5 \mathrm{~min}$. For Western blot analysis, aliquots $(10-20 \mu \mathrm{g})$ of protein extracts were boiled in reducing sample buffer, separated by SDS-PAGE, and blotted on PVDF membranes (Amersham International). Nonspecific binding was reduced by blocking the membranes with TBS- $0.1 \%$ Tween 20 (TBST) containing $5 \%$ nonfat milk powder (TBST-M) at room temperature for $1 \mathrm{~h}$. Membranes were incubated with primary antibody in TBST-M at $4^{\circ} \mathrm{C}$ overnight, washed in TBST-M, and incubated with the appropriate horseradish peroxidase-conjugated secondary antibodies at room temperature for $1 \mathrm{~h}$. After intensive washing with TBST, immunoblots were 
developed using the ECL detection system (Amersham). FAK was immunoprecipitated from RIPA extracts using an agaroseconjugated anti-FAK antibody (Upstate Biotechnology, clone 4.47).

\section{Morphometry}

For morphometric analysis, newborn tibiae from 12 wild-type and 12 mutant animals were processed and investigated on light and electron microscopic levels. The growth plate zones were estimated on morphological criteria and on topographical localization within the long bone (Hunziker et al. 1987). The length of the zones was analyzed as described (Cruz-Orive and Hunziker 1986). To achieve the highest efficiency for the stereological analysis, systematic random sampling protocols were adopted according to Gundersen and Jensen (1987). To estimate the percentage of multinucleated cells among the total cell population in each zone, the proportion of the nuclear profiles showing multinuclear phenomena was counted on positive prints at a final magnification of $960 \times$ photographed from semithin sections.

\section{Acknowledgments}

We thank Takao Sakai for help with X-ray irradiation of Col2a1cre/FN ${ }^{f l / f 1}$ mice; Kathrin Rodgers, Zena Werb, and Gerard Karsenty for discussions and reading the manuscript; Keiko Sakai, Catarina Cramnert, Claudia Nicolai, Véronique Gaschen, and Elke Berger for technical assistance; and Dietmar Vestweber for antibody gifts. C.B. is a Heisenberg Fellow of the Deutsche Forschungsgemeinschaft (DFG). The work was supported by the Swiss National Science Foundation to E.H., and the Max Planck Society, the DFG (SFB 413), and the Fonds der Chemischen Industrie to R.F.

The publication costs of this article were defrayed in part by payment of page charges. This article must therefore be hereby marked "advertisement" in accordance with 18 USC section 1734 solely to indicate this fact.

\section{References}

Aszodi, A., Chan, D., Hunziker, E., Bateman, J.F., and Fässler, R. 1998. Collagen II is essential for the removal of the notochord and the formation of intervertebral discs. J. Cell Biol. 143: 1399-1412.

Aszodi, A., Bateman, J.F., Hirsch, E., Baranyi, M., Hunziker, E.B., Hauser, N., Bösze, Z., and Fässler, R. 1999. Normal skeletal development of mice lacking matrilin 1: Redundant function of matrilins in cartilage? Mol. Cell. Biol. 19: 78417845.

Beier, F., Leask, T.A., Haque, S., Chow, C., Taylor, A.C., Lee, R.J., Pestell, R.G., Ballock, R.T., and LuValle, P. 1999. Cell cycle genes in chondrocyte proliferation and differentiation. Matrix Biol. 18: 109-120.

Bellissent-Waydelich, A., Vanier, M.T., Albiges-Rizo, C., and Simon-Assmann, P. 1999. Talin concentrates to the midbody region during mammalian cell cytokinesis. J. Histochem. Cytochem. 47: 1357-1368.

Bouvard, D., Brakebusch, C., Gustafsson, E., Aszodi, A., Bengtsson, T., Berna, A., and Fässler, R. 2001. Functional consequences of integrin gene mutations in mice. Circ. Res. 89: 211-223.

Brakebusch, C. and Fässler, R. 2003. New EMBO Member's Review: The integrin-actin connection, an eternal love affair. EMBO J. 22: 2324-2333.
Brakebusch, C., Grose, R., Quondamatteo, F., Ramirez, A., Jorcano, J.L., Pirro, A., Svensson, M., Herken, R., Sasaki, T., Timpl, R., et al. 2000. Skin and hair follicle integrity is crucially dependent on $\beta 1$ integrin expression on keratinocytes. EMBO J. 19: 3990-4003.

Brakebusch, C., Bouvard, D., Stanchi, F., Sakai, T., and Fässler, R. 2002. Integrins in invasive growth. I. Clin. Invest. 109: 999-1006.

Brandau, O., Aszodi, A., Hunziker, E.B., Neame, P.J., Vestweber, D., and Fässler, R. 2002. Chondromodulin I is dispensable during enchondral ossification and eye development. Mol. Cell. Biol. 22: 6627-6635.

Cao, L., Lee, V., Adams, M.E., Kiani, C., Zhang, Y., Hu, W., and Yang, B.B. 1999. $\beta 1$-integrin-collagen interaction reduces chondrocyte apoptosis. Matrix Biol. 18: 343-355.

Costell, M., Gustafsson, E., Aszodi, A., Morgelin, M., Bloch, W., Hunziker, E., Addicks, K., Timpl, R., and Fässler, R. 1999. Perlecan maintains the integrity of cartilage and some basement membranes. J. Cell Biol. 147: 1109-1122.

Cruz-Orive, L.M. and Hunziker, E.B. 1986. Stereology for anisotropic cells: Application to growth cartilage. I. Microsc. 143: $47-80$.

Doods, G.S. 1930. Row formation and other types of arrangement of cartilage cells in endochondral ossification. Anat. Record 46: 385-399.

Fässler, R. and Meyer, M. 1995. Consequences of lack of $\beta 1$ integrin gene expression in mice. Genes \& Dev. 9: 18961908.

Fässler, R., Pfaff, M., Murphy, J., Noegel, A.A., Johansson, S., Timpl, R., and Albrecht, R. 1995. Lack of $\beta 1$ integrin gene in embryonic stem cells affects morphology, adhesion, and migration but not integration into the inner cell mass of blastocysts. J. Cell Biol. 128: 979-998.

Fujiwara, K., Porter, M.E., and Pollard, T.D. 1978. $\alpha$-Actinin localization in the cleavage furrow during cytokinesis. J. Cell Biol. 79: 268-275.

Giancotti, F.G. and Ruoslahti, E. 1999. Integrin signaling. Science 285: 1028-1032.

Grashoff, C., Aszódi, A., Sakai, T., Hunziker, E.B., and Fässler, R. 2003. Integrin-linked kinase regulates chondrocyte shape and proliferation. EMBO Reports 4: 432-438.

Gritly-Linde, A., Lewis, P., McMahon, A.P., and Linde, A. 2001. The whereabouts of a morphogen: Direct evidence for shortand graded long-range activity of hedgehog signaling peptides. Dev. Biol. 236: 364-386.

Gundersen, H.J. and Jensen, E.B. 1987. The efficiency of systematic sampling in stereology and its prediction. I. Microsc. 147: 229-263.

Hedman, K., Johansson, S., Vartio, T., Kjellen, L., Vaheri, A., and Hook, M. 1982. Structure of the pericellular matrix: Association of heparan and chondroitin sulfates with fibronectinprocollagen fibers. Cell 28: 663-671.

Hirsch, M.S., Lunsford, L.E., Trinkaus-Randall, V., and Svoboda, K.K. 1997. Chondrocyte survival and differentiation in situ are integrin mediated. Dev. Dyn. 210: 249-263.

Hunziker, E.B, Schenk, R.K., and Cruz-Orive, L.M. 1987. Quantitation of chondrocyte performance in growth-plate cartilage during longitudinal bone growth. J. Bone Joint Surg. Am. 69: $162-173$.

Hynes, O.R. 2002. Integrins: Bi-directional, allosteric signaling machines. Cell 110: 673-687.

Karsenty, G. and Wagner, E.F. 2002. Reaching a genetic and molecular understanding of skeletal development. Dev. Cell 2: 389-406.

Lanske, B., Karaplis, A.C., Lee, K., Luz, A., Vortkamp, A., Pirro, A., Karperien, M., Defize, L.H., Ho, C., Mulligan, R.C., et al. 
1996. PTH/PTHrP receptor in early development and Indian hedgehog-regulated bone growth. Science 273: 663-666.

Li, C., Chen, L., Iwata, T., Kitagawa, M., Fu, X.-Y., and Deng, C-X. 1999. A Lys644Glu substitution in fibroblast growth factor receptor 3 (FGF3) causes dwarfism in mice by activation of STATs and ink4 cell cycle inhibitors. Hum. Mol. Genet. 8: 35-44.

Loeser, R.F. 2000. Chondrocyte integrin expression and function. Biorheology 37: 109-116.

Long, F., Zhang, X.M., Karp, S., Yang, Y., and McMahon, A.P. 2001. Genetic manipulation of hedgehog signaling in the endochondral skeleton reveals a direct role in the regulation of chondrocyte proliferation. Development 128: 5099-5108.

Morgan, S.M., Samulowitz, U., Darley, L., Simmons, D.L., and Vestweber, D. 1999. Biochemical characterization and molecular cloning of a novel endothelial-specific sialomucin. Blood 93: 165-175.

Ornitz, D.M. and Marie, P.J. 2002. FGF signaling pathways in endochondral and intramembranous bone development and human genetic disease. Genes \& Dev. 17: 926-940.

Parsons, J.T., Martin, K.H., Slack, J.K., Taylor, J.M., and Weed, S.A. 2000. Focal adhesion kinase: A regulator of focal adhesion dynamics and cell movement. Oncogene 19: 56065613.

Pons, S., Trejo, J.L., Martinez-Morales, J.R., and Marti, E. 2001. Vitronectin regulates Sonic hedgehog activity during cerebellum development through CREB phosphorylation. Development 128: 1481-1492.

Potocnik, A.J., Brakebusch, C., and Fassler, R. 2000. Fetal and adult hematopoietic stem cells require $\beta 1$ integrin function for colonizing fetal liver, spleen, and bone marrow. Immunity 12: 653-663.

Sakai, K., Hiripi, L., Glumoff, V., Brandau, O., Eerola, R., Vuorio, E., Bösze, Z., Fässler, R., and Aszodi, A. 2001. Stage-and tissue-specific expression of a Col2al-Cre fusion gene in transgenic mice. Matrix Biol. 19: 761-767.

Sakai, T., Johnson, K.J., Murozono, M., Sakai, K., Magnuson, M.A., Wieloch, T., Cronberg, T., Isshiki, A., Erickson, H.P., and Fässler, R. 2001. Plasma fibronectin supports neuronal survival and reduces brain injury following transient focal cerebral ischemia but is not essential for skin-wound healing and hemostasis. Nat. Med. 7: 324-330.

Sato, N., Yonemura, S., Obinata, T., Tsukita, S., and Tsukita, S. 1991. Radixin, a barbed end-capping actin-modulating protein, is concentrated at the cleavage furrow during cytokinesis. J. Cell Biol. 113: 321-330.

Shakibaei, M. 1998. Inhibition of chondrogenesis by integrin antibody in vitro. Exp. Cell. Res. 240: 95-106.

St-Jacques, B., Hammerschmidt, M., and McMahon, A.P. 1999. Indian hedgehog signaling regulates proliferation and differentiation of chondrocytes and is essential for bone formation. Genes \& Dev. 13: 2072-2086.

Su, W.C., Kitagawa, M., Xue, N., Xie, B., Garofalo, S., Cho, J., Deng, C., Horton, W.A., and Fu, X.Y. 1997. Activation of Stat 1 by mutant fibroblast growth-factor receptor in thanatophoric dysplasia type II dwarfism. Nature 386: 288-292.

Velling, T., Risteli, J., Wennerberg, K., Mosher, D.F., and Johansson, S. 2002. Polymerization of type I and III collagens is dependent on fibronectin and enhanced by integrins $\alpha 11 \beta 1$ and $\alpha 2 \beta 1$. J. Biol. Chem. 277: 37377-37381.

Vortkamp, A. 2001. Interaction of growth factors regulating chondrocyte differentiation in the developing embryo. Osteoarth. Cart. 9 Suppl A: S109-S117.

Vortkamp, A., Lee, K., Lanske, B., Segre, G.V., Kronenberg, H.M, and Tabin, C.J. 1996. Regulation of rate of cartilage differentiation by Indian hedgehog and PTH-related protein.
Science 273: 613-622.

Yang, C., Li, S.W., Helminen, H.J., Khillan, J.S., Bao, Y., and Prockop, D.J. 1997. Apoptosis of chondrocytes in transgenic mice lacking collagen II. Exp. Cell Res. 235: 370-373. 


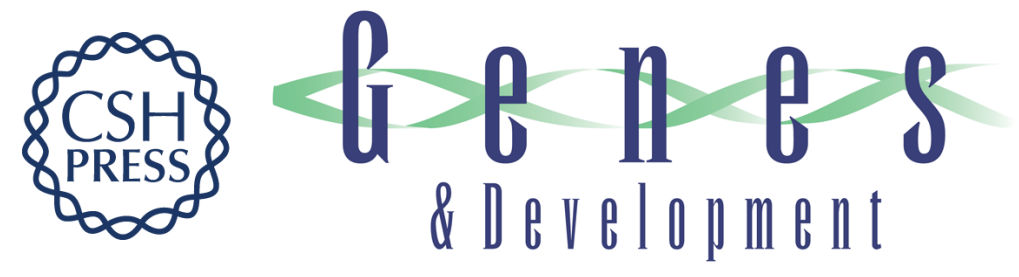

\section{$\beta 1$ integrins regulate chondrocyte rotation, G1 progression, and cytokinesis}

Attila Aszodi, Ernst B. Hunziker, Cord Brakebusch, et al.

Genes Dev. 2003, 17:

Access the most recent version at doi:10.1101/gad.277003

Supplemental
Material http://genesdev.cshlp.org/content/suppl/2003/09/09/17.19.2465.DC1

References This article cites 42 articles, 19 of which can be accessed free at: http://genesdev.cshlp.org/content/17/19/2465.full.html\#ref-list-1

License

Email Alerting

Receive free email alerts when new articles cite this article - sign up in the box at the top Service right corner of the article or click here.



